
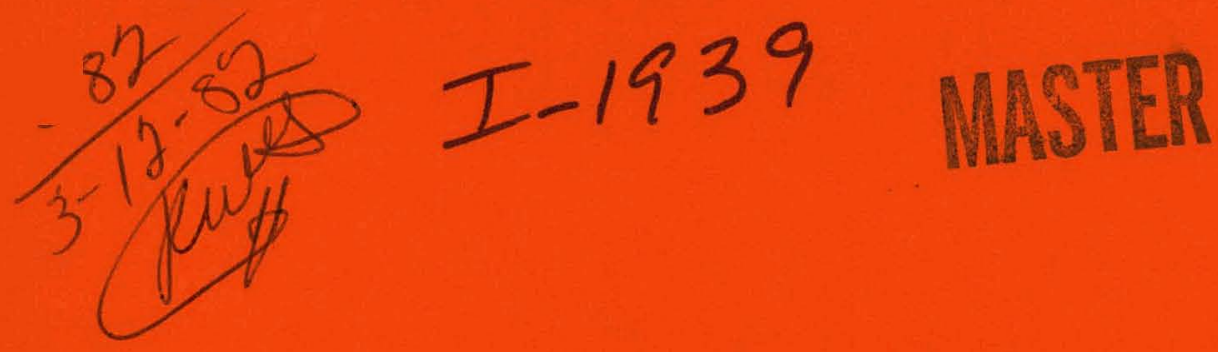

DR 335

\title{
AN EFFECTIVE METHOD FOR MHD RETROFIT OF POWER PLANTS \\ by
}

G. F. Berry, C. B. Dennis,

T. R. Johnson, and V. Minkov

\section{NOIICE}

PORTIONS OF TMIS PEPORT ARE ILLEGIBLE. It has been remroduced from the best available copy to permit the broadest possible availability.

ARGQNNE MATIONAL LABORATORY

ARGONNE NATIONAL LABORATORY, ARGONNE, ILLINOIS

Prepared for the U. S. DEPARTMENT OF ENERGY/Fossil Energy MHD Division 


\section{DISCLAIMER}

This report was prepared as an account of work sponsored by an agency of the United States Government. Neither the United States Government nor any agency Thereof, nor any of their employees, makes any warranty, express or implied, or assumes any legal liability or responsibility for the accuracy, completeness, or usefulness of any information, apparatus, product, or process disclosed, or represents that its use would not infringe privately owned rights. Reference herein to any specific commercial product, process, or service by trade name, trademark, manufacturer, or otherwise does not necessarily constitute or imply its endorsement, recommendation, or favoring by the United States Government or any agency thereof. The views and opinions of authors expressed herein do not necessarily state or reflect those of the United States Government or any agency thereof. 


\section{DISCLAIMER}

Portions of this document may be illegible in electronic image products. Images are produced from the best available original document. 
The facilities of Argonne National Laboratory are owned by the United States Government. Under the terms of a contract (W-31-109-Eng-38) among the U.S. Department of Energy, Argonne Universities Association and The University of Chicago, the University employs the staff and operates the Laboratory in accordance with policies and programs formulated, approved and reviewed by the Association.

\section{MEMBERS OF ARGONNE UNIVERSITIES ASSOCIATION}

The University of Arizona

Carnegie-Mellon University

Case Western Reserve University

The University of Chicago

University of Cincinnati

Illinois Institute of Technology

University of Illinois

Indiana University

The University of Iowa

Iowa State University
The University of Kansas

Kansas State University

Loyola University of Chicago

Marquette University

The University of Michigan

Michigan State University

University of Minnesota

University nf Missnuri

Northwestern University

University of Notre Dame
The Ohio State University

Ohio University

The Pennsylvania State University

Purdue University

Saint Louis University

Southern Illinois University

The University of Texas at Austin

Washington University

Wayne State University

The University of Wisconsin-Madison

NOTICE

This report was prepared as an account of work sponsored by an agency of the United States Government. Neither the United States Government nor any agency thereof, nor any of their employees, makes any warranty, express or implied, or assumes any legal liability or responsibility for the accuracy, completeness, or usefulness of any information, apparatus, product, or process disclosed, or represents that its use would not infringe privately owned rights. Reference herein to any specific commercial product, process, or service by trade name, trademark, manufacturer, or otherwise, does not necessarily constitute or imply its endorsement, recommendation, or favoring by the United States Government or any agency thereof. The views and opinions of authors expressed herein do not necessarily state or reflect those of the United States Government or any agency thereof.

Printed in the United States of America

Available from

National Technical Information Service

U. S. Department of Commerce

5285 Port Royal Road

Springfield, VA 22161

NTIS price codes

Printed copy: A05

Microfiche copy: A01 
Distribution Categories:

Coal Conversion and Utilization-

MHD (UC-90g)

Energy Conversion (UC-93)

ANL/MHD-81-10

ARGONNE NATIONAL LABORATORY

9700 South Cass Avenue

Argonne, Illinois 60439

AN EFFECTIVE METHOD FOR

MHD RETROFIT OF POWER PLANTS

by

G. F. Berry, C. B. Dennis,

$T$. R. Johnson, and V. Minkov

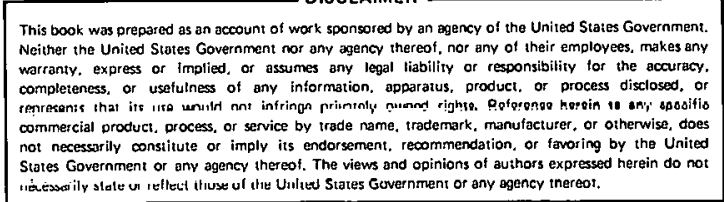

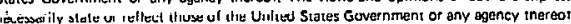

ANL/MHD- $-81-10$

DE82 $008570^{\circ}$

October 1981 


\section{THIS PAGE WAS INTENTIONALLY LEFT BLANK}




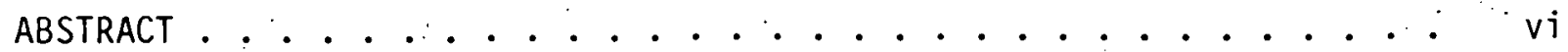

EXECUTIVE SUMMARY.............................. vii

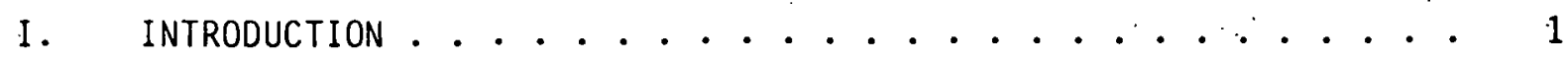

II. APPROACH TO MHD RETROFIT ..................... 3

III. VERMILION POWER STATION BOILER \#I: CANDIDATE FOR RETROFIT: . . . 7

A. Description of Plant. ........... . 7

B. Computer Simulation of Vermilion Boiler \#1........ 11

IV. MHD RETROFIT OF VERMILION BOILER \#1. ......... 17

A. Retrofit Constraints. . . . . . . . . . . . . 17

B. Description of MHD Retrofit Plant ........... 18

C. Distinguishing Features of ANL Retrofit Design. . ...... 29

D. Modifications to the Existing Boiler. ......... 31

E. New Components to be Added for Retrofit . . . . ... 33

V. PLANT FEATURES FAVORABLE FOR RETROFIT. . . . . . . . . 39

VI. COST EFFECTIVENESS OF MHD RETROFIT ............ 41

A. Cost of MHD Retrofit vs. New Conventional Plant ...... 41

B. Cost of MHD Retrofit vs. Scrubber Retrofit. . . . . . . 48

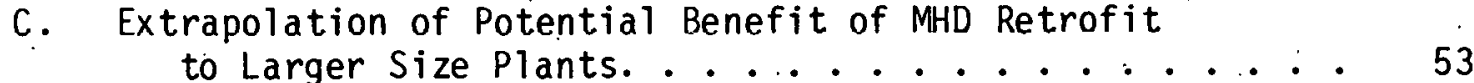

D. Potential Impact of MHD Retrofit on Coal Utilization. . . 63

SUMMARY. . . . . . . . . . . . . . . 69

REFERENCES ............................. 71

APPENDIX: COMPUTER ANALYSIS .................. 75 
1. Vermilion Power Plant \#1 - $=$ Main Floor Plan ......... 9

2. Vermilion Power Plant \#1 -- Elevation View ......... 10

3. Vermilion Power Plant \#1 -- Boiler Arrangement. ......... 11

4. Vermilion Power Plant \#1 -- Schematic ............ 14

5. Retrofit Configuration "A" - Schematic ......... 21

6. Retrofit Configuration "B" -- Schematic .......... 23

7. Vermilion Retrofit -- Elevation View ......................

8. Vermilion Retrofit -- Areas of New Buildings. ........ 36

9. Relative Change in the Cost of MHD Retrofits of Increasing

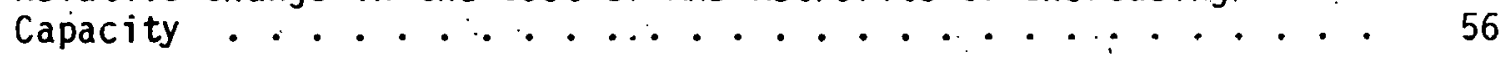

10. Relative Change in Plant Efficiency for MHD Retrofits of Increasing

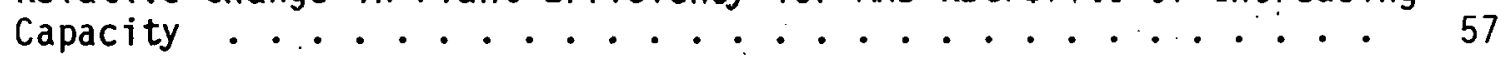

11. Relative Gain in Total Equivalent Capital Investment for MHD Retrofits of Increasing Capacity ............ 64 


\section{LIST. OF TABLES}

1... Zeigler Mine Coal Analysis -- Vermilion Power Plant. . . . . . . 12

2. Cómparison Between Aväilable and Calculated Surface Areas . : . : 13

3. Vermilion \#1 -- Available State Points Information . . . . . . 15

4. . Vermilion \#1 -- Calculated State Points . . . . . . . . 16

5. Summary of Results. . . . . . . . . . . . 25

6. Retrofit "A" .- Calculated State Points . . . . . ..... 26

7. Retrofit "B" -- Calculated State Points ... . . . . . . . 27

8. Power Consumption of Auxiliary Equipment. . . . . . . . . 28

9. Calculated Particle Deposition in Conventional Boiler...... 30

10. Life-Cycle Cost Comparison of New Coal-Fired Unit and MHD Retrofit 43

11. Economic Parameters and Design Basis. .......... 44

12. Direct Construction Costs for a New Coal-Fired Unit . . . . . 45

13. Estimated Retrofit cost . . . . . . . . . . . 46 46

14. Alternatives for Second Life-Cycle Cost Study . . . . . . . 50

15. Summary of Operations and Maintenance costs for Base Year . . . 50

16. Summary of Data by Alternative for Base Year. . . . . . . . 51

17. General Financial Assumptions . . . . . . . . . . . 52

18. Summary of Comparative Financial Results............. 5 ?

19. Cost Comparison -- 70/240-MW (electrical) Power System. . . . 54

20. Cost Comparison -- 90/300-MW (electrical) Power System. . . . . 58

21. Cost Comparison -- 150/500-MW (electrical) Power System. . . . 59

22. Cost Comparison -- 210/700-MW (electrical) Power System . . . 60

23. Cost Comparison -- 270/900-MW (electrical) Power System ..... 61

24. Cost Comparison -- 330/1100-MW (electrical) Power System. . . . 62

25. Electricity Generation By-Fuel Type . . . . . . . . 66 
Retrofitting existing power plants with an open-cycle MHD system has been re-examined in light of recent developments in the heat and seed recovery technology area. A new retrofit cycle configuration has been developed which provides for a direct gas-gas coupling; also, the MHD topping cycle can be decoupled from the existing plant for either separate or joint operation. As an example; the MHD retrofit concept has been applied to Illinois Power Company's Vermilion Station \#1, a coal-fired power plant presently in operation: Substantial increases in efficiency have been demonstrated and the economic validity of the MHD retrofit-approach has been establi.shed. 
A new approach to retrofitting a coal-fired MHD topping cycle to an existing power plant was investigated. In this approach, all or a large fraction of the hot gas from the MHD cycle flows through the conventional steam boiler, which then operates in its normal manner. The added components include the MHD.combustor and channel with their supporting facilities, and a new steam generator that produces power for the oxygen enrichment plant, for the MHD oxidant compressor, and for sale. Recently obtained experimental data on tube fouling by seed and ash and sootblower performance indicate that the deposits formed in the conventional plant can be controlled by conventional sootblower, and the MHD steam generator can be designed to operate satisfactorily despite the tenacious seed deposits that are expected where the gas temperature are above the seed melting point.

The retrofitted plant is capable of operating with or without the MHD channel and steam generator. When operating with these MHD topping cycle components, the plant will produce a total of $80-240 \%$ more electrical power than the original plant while increasing efficiency by 3 to 5 points. These considerations make MHD retrofitting attractive for increasing system capacity to meet rising demand without the need to develop or license new plant sites. The combined retrofitted plant can meet regulations 1 imiting $\mathrm{NO}_{x}, \mathrm{SO}_{2}$ and particle emissions while burning high sulfur coal.

The higher efficiency and the capability of burning less costly coal results in a significant economic benefit despite the higher unit capital cost of the MHD plant compared to a conventional coal-fired unit. Cost studies were made comparing MHD retrofit options with several more conventional alternatives for meeting environmental regulations and increasing capacity. These studies were based on retrofitting a specific coal-fired plant - the Vermilion Boiler \#1 of Illinois Power Company. This unit, built in 1950, has a 1450 psig $/ 1005^{\circ} \mathrm{F} / 1005^{\circ} \mathrm{F}$ steam system and produces a nominal net output of $70 \mathrm{MW}$. Conceptual designs of the MHD topping components were developed. The performance of the combined-cycle plants were calculated by using the ANL/MHD Systems Analysis Code was also used to accurately simulate the existing plant. The costs of the retrofit components were based on estimates for a 
complete first-of-a-kind plant but lower capital costs would be expected as the MHD design matures. Compared to building a new conventional plant with a scrubber on a new site, the retrofitted plant with the same total capacity of $240 \mathrm{MW}(e l e c t r i c a l)$ showed a lower total revenue requirement over the plant life with a gain dependent on the physical condition of the existing plant. MHD retrofitting had a clear financial gain as well as a large increase in capacity compared to switching to higher cost, low sulfur coal or adding a limestone scrubber to the existing plant to meet $\mathrm{SO}_{2}$ emission limitations. The payback period. for a 240 MW retrofit of the 70 MW Vermilion Boiler \#1 was 14 yrs with an internal rate of return of $12.8 \%$.

The advantage of MHD retrofitting increases as the plant capacity. inr.reases. An extrapnlation, nf the result.s from the const. study, is presenter to project the financial gain from retrofitting plants larger than 70 MWe. An increase in gain from 4.5\% (70 MW(electrical)) to 13-23\% (330 MW(electrical)) has been projected.

This study indicates that a retrofit concept in which some of the MHD exhaust gas passes through the existing steam generator is technically feasible and has significant economic advantages over several conventional alternatives for meeting increased demand or environmental restrictions. MHD retrofitting appears to have a large potential market, and if widely applied, it would result in more efficient utilization of our national coal resources and in the capability to burn high sulfur coal. 


\section{INTRODUCTION}

MHD retrofit appears to be an attractive approach to both further development of MHD technology and also to upgrade existing coal-fired power plants. It provides an avenue for early commercialization of the MHD concept to the electric power industry. Retrofitting would provide a rigorous demonstration of the technological readiness of the MHD technology and also accurace economic data necessary to project the comparative cost of commercial-scale MHD power plants versus other energy alternatives that are being considered.

Steady progress that has been achieved [1] in the development of MHD technology is underscored by the fact that after successful tests with a 10 MW(electrical) channel [2,3] the U.S.S.R. is proceeding to build a commercialsize MHD power plant $1000 \mathrm{MW}$ (thermal) [4]. The U.S. has al so made long duration channel tests [5] and recently has initiated component testing at the 2050 MW(thermal) level at the CDIF [6] and CFFF [7] Test Facilities.

There are also the near-term benefits that could evolve from MHD retrofitting. If an MHD retrofit application could increase plant efficiency by 5$10 \%$ (typically from $33 \%$ to $38-43 \%$, as indicated by this study), and also double (or triple) the plant capacity, the need to develop new power plants in answer to slight increases in demand could be greatly reduced -- postponing the commitment of larger amounts of capital that would otherwise be required for building new plants. The refurbishing of the existing plants being retrofitted would also extend the life of the plant and obviate the need for development of new sites and lengthy licensing processings associated with new plants.

Still another very important benefit that would accrue from MHD retrofit is the ability to meet all existing environmental regulations (including $\mathrm{SO}_{2}$ emission standards), even when burning high-sulfur coal. Retrofitting with MHD is, clearly, not the only option available for improving an existing plant with flue gas desulfurization (FGD) scrubbers would satisfy the requirements, although at lower plant efficiency than obtained by retroftting with MHD. Regardless of the option chosen, increasing the use of coal at an existing 
coal-fired plant will require implementátion of a pollution control method that brings the plant into compliance with new environmental guidelines. The available information indicates that the "built-in" mechanism for control of $\mathrm{NO}_{x}$ and $\mathrm{SO}_{2}$ in MHD power plants can readily meet even the more stringent NSPS.

In view of the potential benefits accruing from MHD retrofit, a study was undertaken whose primary objectives were to, a) develop a conceptual design of a retrofit MHD topping cycle that would be site specific, and b) make a cost study of the retrofit to determine if there is an economic incentive to pursue this approach. 


\section{APPROACH TO RETROFIT}

Previous studies of various approaches to MHD retrofit [8] concludes that for a gas-to-gas coupling (exhaust from MHD topping cycle flows directly into existing boiler), excessive modification to the existing boiler would be required, reducing or eliminating any economic potential for retrofitting an MHD topping cycle to an existing çoal-fired power plant. The study has based upon specific assumptions concerning design limiations and operational parameters and characteristics which strongly influenced the outcome of the studies. For example, it was assumed that the particle loading of the combustion gas exiting from the MHD flow train prohibited the use of the existing boiler tube spacings, and that the corrosive character of the seed deposits was such that existing tube materials could not withstand the attack for acceptable periods of time. The study concluded that a retrofit, based upon a steam-to-steam coupling and.separate gas paths, was the most viable approach.

Since that study was completed, considerable new information has been developed which suggests that the gas-to-gas retrofit of existing plants is possible and can be realistically accomplished.

Long-duration laboratory corrosion tests under a wide range of simulated MHD conditions have shown that coded, iron-base alloys will give satisfactory service in the MHD steam plant. Carbon steel and low-chromium steel alloys appear to be suitable for the water walls of the radiant boiler, where fuelrich conditions exists, if the metal temperature does not exceed $710^{\circ} \mathrm{F}(650 \mathrm{~K})$ [9]: At higher temperatures, most metal alloys, including high chromium alloys, suffer rapid attack in the reducing, sulfur-rich atmosphere. High chromium, iron-base alloys (e.g., Type 300 stainless steels) have adequate resistance to sulfidation-types of corrosion and will be suitable for the final superheater and reheater [10]. These alloys have also exhibited resistance toward "hot corrosion" attack in the alkali-rich, MHD environment. Low chromium steels will give satisfactory service in the initial (primary) superheater and reheater, although more high chromium alloys will be needed for the MHD plant than for a conventional coal-fired unit. 
The control of seed and slag deposition (fouling) is of critical importance in any retrofit approach. Because of the high proportion $(80-90 \%)$ of $\mathrm{K}_{2} \mathrm{SO}_{4}$ in the entrained materials in MHD plants, the fouling problems downstream of the radiant boiler are expected to be considerably different from those encountered in conventional plants where the fouling results from the deposition of ash constituents. Three deposition regimes have been defined based on whether the gas temperature is above or below the seed melting point (melting point of pure $\mathrm{K}_{2} \mathrm{SO}_{4}$ is $1950^{\circ} \mathrm{F}(1340 \mathrm{~K})$ ), and whether the deposit surface can be maintained above the seed melting point. Tests at ANL [11] indicate that deposits formed by entrained solid seed particles tend to have low densities and low strengths, and, ronsoquently, it should be pusstble tu. control their accumulation by conventional means, e.g., sootblowers. Deposits formed by entrained liquid particles are dense and strongly adherent dild, thus, may be difficult to: remove. However, at gas temperatures sufficientiy above the seed melting point, the deposit surface will become liquid and the depositing seed particles can run off the tube. If a deposit with a steadystate thickness that does not seriously impede heat transfer and gas flow can be maintained (e.g., in sections having wide tube spacings), the removal of these dense deposits will not be necessary.

Analogous seed deposit regimes have been identified in Soviet test facility $[12,13]$, although somewhat different fouling characteristics have been observed, because their combustion gases were slag-and sulfur-free. The high temperature sections of the $U-25$ boiler performed satisfactorily with liquid deposits of $\mathrm{K}_{2} \mathrm{CO}_{3}$, but troublesome deposits formed at gas temperatures between about $2050^{\circ} \mathrm{F}(1400 \mathrm{~K})$ and the melting point of $\mathrm{K}_{2} \mathrm{CO}_{3}$ $\left(1635^{\circ} \mathrm{F}(1165 \mathrm{~K})\right)$.

Considering the recent information that has ovolved from the lleat and Seed Recovery Program [14] and from the system analysis component lludeling group $[15,16]$, the following general guidelines were adopted for developing an MHD retrofit to a conventional plant.

One of the primary objectives of any retrofit project is the utilization of as much of the existing. plant equipment as is feasible. Only this approach can maximize the cost benefit of retrofitting. This consideration establishes 
what demand may be imposed on the existing equipment after implementation of the MHD topping cycle. The maximum gas mass flow rate through, the conventional boiler should be no more than $10 \%$ greater than the typical design value. This limit is set on the basis of a gas velocity constraint to prohibit excessive erosion resulting from particles entrained in the gas. (Analysis has determined that for full utilization of existing turbines and boiler, the optimum gas mass flow rate through the conventional plant is greater than the maximum value permitted by the erosion limit.) Because of the change in gas composition, it can be presumed that this limit will be altered slightly in a more rigorous analysis. During operation in the MHD mode, metal temperatures of the conventional sections should be comparable to those resulting from operation in the conventional mode. The existing boiler steam conditions should be maintained under retrofit mode operations.

Further, because of the commitment of the utilities to guaranteed power production and the fact that the MHD concept has not yet been completely demonstrated, it is imperative that the first MHD retrofits be designed for both separate (conventional mode) and joint (MHD retrofi.t mode) operation. In other words, the conventional plant must operate effectively, whether or not the MHD topping plant is in operation. This requirement suggests provision for two steam.cycles (conventional and MHD sections), decoupled, although at the same throttle conditions, to promote operability and maintainability. It should be noted that this restriction, requiring provision for separate operation, may not result in a design which has an efficieny comparable to a new MHD plant. Steam cycle decoupling is a reasonable guidel ine for at least the first MHD retroril pruject, in order that adjustments to the existing steam plant will be minimized. It should be noted, further, that implementation of this "separate-plus-joint" guideline for the initial MHD retrofit project will facilitate operating the MHD cycle to meet peak loads, yet leave the conventional boiler intact to maintain output when the MHD topping cycle is out of service. This would prove an effective arrangement for obtaining in-service operating data for the MHD components, yet allowing sufficient MHD downtime for studying the effects of that desired in-service operational experience on the MHD components while not affecting conventional plant uptime. 
In regard to the fouling issue, recent detailed analys is $[14,17]$ indicates that the particle deposition and ensuing fouling can be effectively contained in the semi-radiant and convective sections of the conventional steam generator, if the combustion gases enter at the proper temperature. To prevent the entrained potassium seed materials from causing severe fouling in the conventional steam heaters, the gas must enter the first convective tube bank at a temperature below the freezing point of $\mathrm{K}_{2} \mathrm{SO}_{4}, 1950^{\circ} \mathrm{F}(1340 \mathrm{~K})$. Experiments. have shown that deposits formed from entrained solid seed particles can be removed with, at most, minor modifications to the conventional sootblowers and reconstruction of the electrostatic precipoators (ESP). The moṣt severe fouling problems will be confined to the MHD train. which will be designed to cope with dense, strongly adherent seed deposits formed at gas temperatures that are above the melting point of the seed. The. retrofit design approach adopted assures that seed deposition does not present a more serious problem than could be expected at a new MHD plant.

The MHD retrofit design should also provide maximum economic advantage for the MHD retrofit after satisfaction of all operational constraints. It has been assumed, for purposes of this initial study, that this desire translates into a requirement that the low-grade heat be fully utilized. ( $A$ thorough economic study might indicate otherwise, but that prospect is considered unlikely at present.)

After implementation of the MHD retrofit, the plant must meet the same transient electrical load requirements as it did prior to retrofit. Operation must be guaranteed for all conditions regardless of possible instabilities in coal properties. All environmental regulations must be satisfied. Finally, without special tax incentives or exceptions to regulatory rate changes, each power plant that is a candidate for retrofitting has a minimum acceptable rate to return; the rate of return for the retrofit design must be at least comparable with that expected of a new conventional power plant of equivalent capacity. 
III. VERMILION POWER STATION BOILER \#1: CANDIDATE FOR RETROFIT

At the initiation of the retrofit study, discussions were held with representatives of several utilities, including Illinois Power Company (IPC), to obtain suggestions for power plants that might be suitable for adding an MHD topping cycle. It was suggested that the candidate plant should be reasonably prototypic of modern coal-fired units, should be nearing the end of its useful life, and should be relatively small to minimize the modification costs. Two plants were offered by IPC: the Vermilion \#1 and the very similar Hennepin \#1 unit. Vermilion was selected because the area around the plant was less restricted.

To demonstrate feasibility of the MHD retrofit potential, Argonne National Laboratory undertook the project of developing a retrofit design. campatible with Boiler \#l at Vermilion Power Station (Oakwood, IL). Because of conflicting specifications, two designs were ultimately developed. Details of the two retrofit design are presented in the following sections.

\section{A. Description of Plant}

Vermilion Power Plant \#1 of Illinois Power Company was designed by Combustion Engineering and put into operation in the early 1950s. (Unit \#2 was added at a later date). The boiler drives an 80-MW (electrical) turbine with $1450 \mathrm{psig} / 1005^{\circ} \mathrm{F} / 1005^{\circ} \mathrm{F}(100 \mathrm{~atm} / 814 \mathrm{~K} / 814 \mathrm{~K})$ steam and is fired with Illinois coal of sulfur content low enough to require only ESPs for flue gas cleanup. The dry bottom furnace operates with an induced-draft fan. Soot blowers have to be operated only every 4 hours; examination of the boiler and superheater surface through viewing ports shows very little slag and ash accumulation.

The steam generator facility has only one furnace wall (an east sidewall) sufficiently free of pipes and obstructions to allow passage of an MHD duct. A large open area alongside the coal conveyor is adjacent to the wall where the MHD duct could enter the facility. See Figures 1 and 2 for the floor plan and cross-sectional view of the Vermilion plant components. Figure 3 shows the vermilion boller drrarigement. 
At reduced load, steam balance between boiling and superheating is controlled by tilting the 12 burners and by steam attemperation. The superheater and reheater platens are spaced 15-18 inches apart, and the air heater is a metallic fire-tube heat exchanger. Hot air is discharged at $550^{\circ} \mathrm{F}(560 \mathrm{~K})$ and is split to the coal dryer and the burners.

The contract of the former supplier of coal to the Vermilion plant was terminated because the sulfur content of the coal was higher than allowable, and burning it would have required installation of a gas scrubber. The plant now burns low sulfur Ziegler Mine coal of the analysis shown in Table 1 . It is screened and crushed at the mine and trucked 60 miles to the plant. At the plant the $-3 / 4$ inch coal, is bowl-milled to $50 \%,-200$ mesh and pneumatically transported directly to the burners. The coal is continuously fed fiüu liue storage hoppers in the power plant building. A continuous supply of hot air is piped from the air heater to the pulverizer dryer and used to ronvey the coal into the burner. After burning, soot, slag, and fly ash are mixed with water and sluiced to landfill retention ponds.

The feedwater heater arrangement contains four feedwater heaters and a deaerator. The high pressure heater contains a desuperheater section while the next feedwater header (located directly after deaerator) has a drain cooler. The lowest pressure feedwater heater is a pumped heater. The main booster pump is situated directly after the deaerator while the condensate pumps, are located between the rnndenser woll and the stcam jet air.ejeclur. The turbine heat rate for this cycle arrangement is $8151 \mathrm{Btu} / \mathrm{kW}-\mathrm{hr}$.

\section{B. Computer Simulation of Vermilion Boiler \#1}

Accurate simulation of the Vermilion \#1 plant in both design and offdesign modes (was developed with the ANL/MHD Systems Code $[18,19,20]$; this was a necessary step in developing a realistic retrofit design, because the results of the simulation are, in effect, used as input for developing the retrofit designs. The analyses of the retrofit designs are made dependent, in every case, upon an accurate simulation of the Vermilion \#1 plant. 'To obtain an accurate simulation of the Vermilion plant, the systems code was used to vary the amount of heat transferred in each component land the resulting exit 


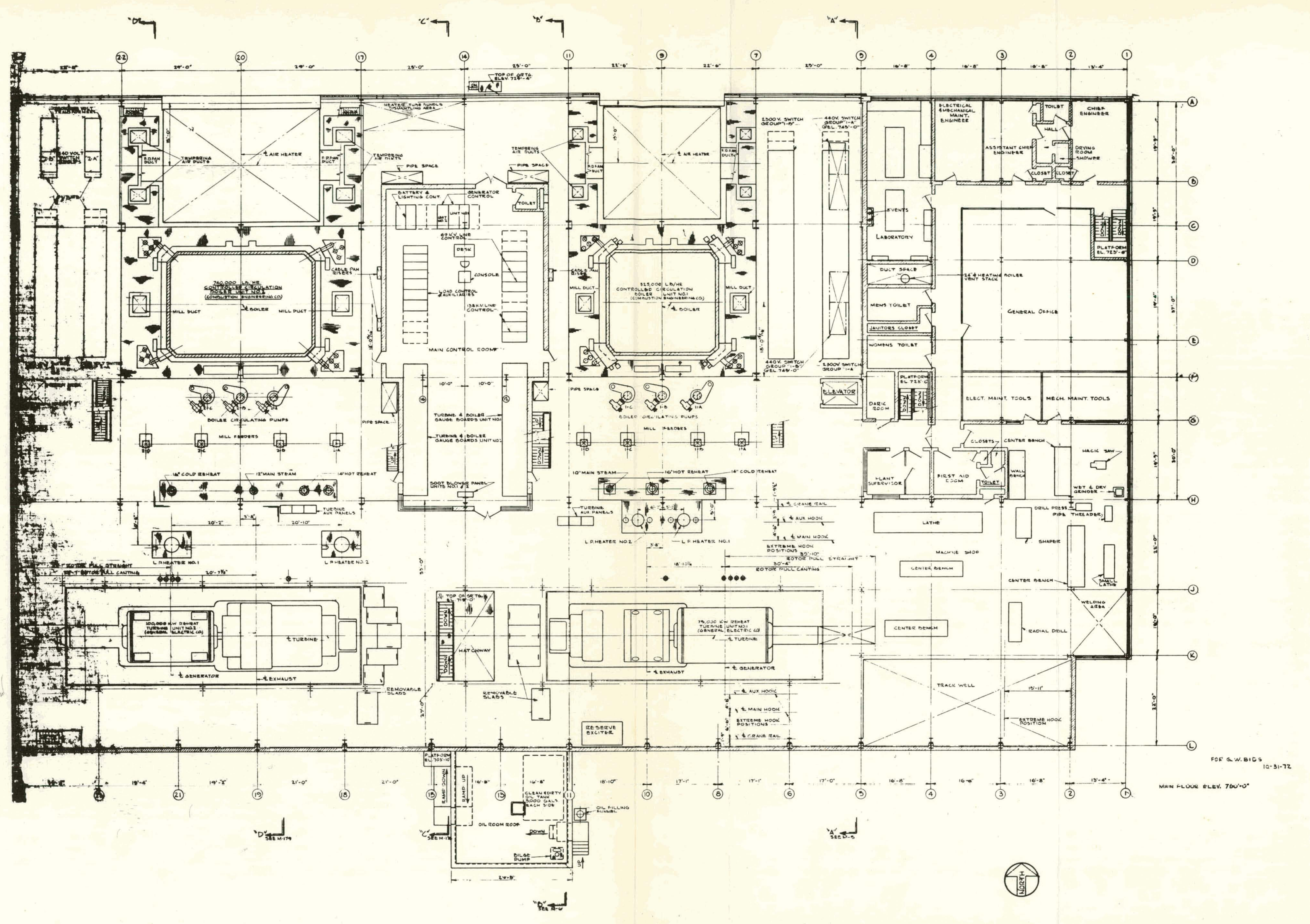

Figure 1: Vermilion Power Plant \#1 -- Main Floor Plan 


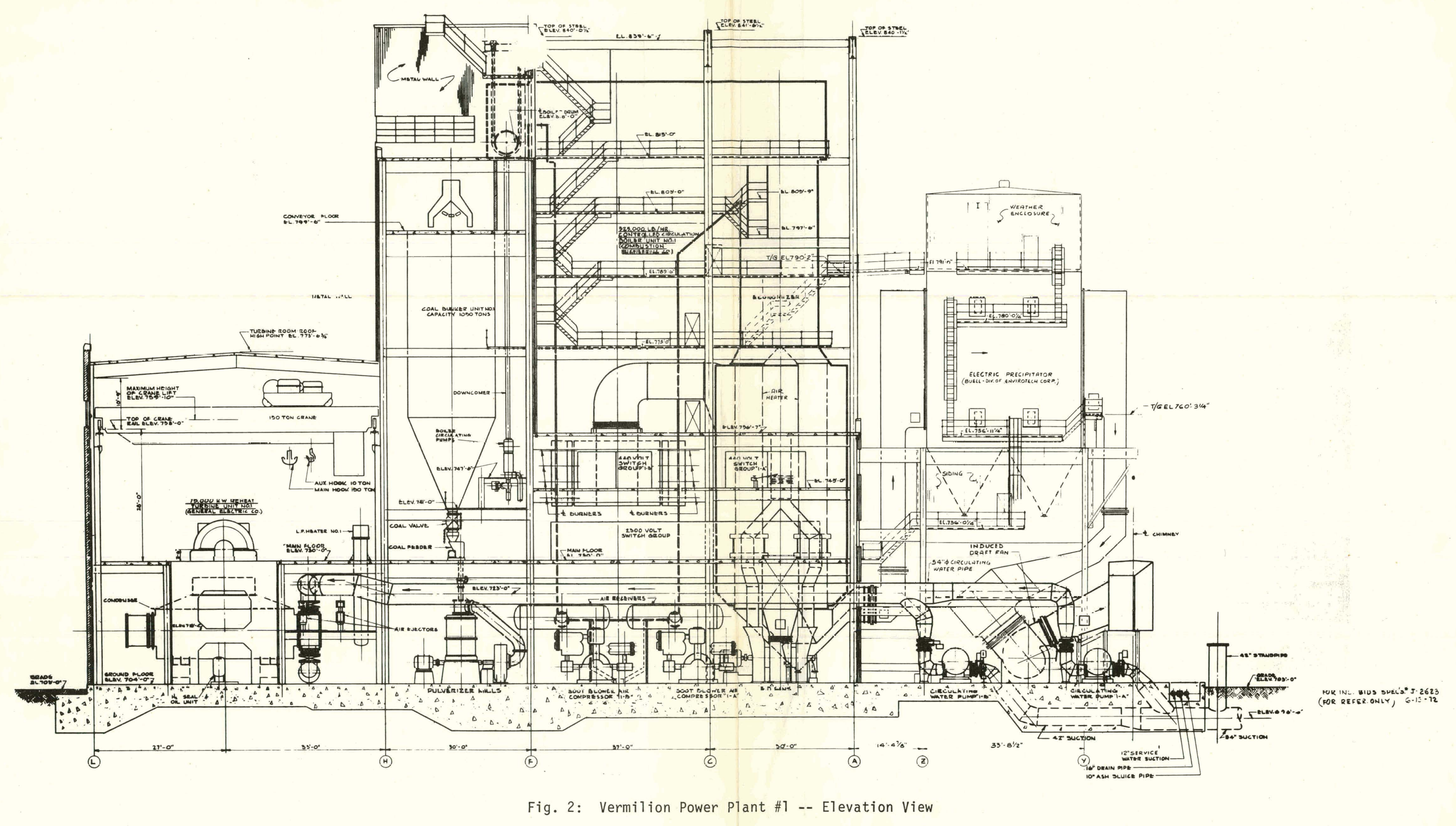




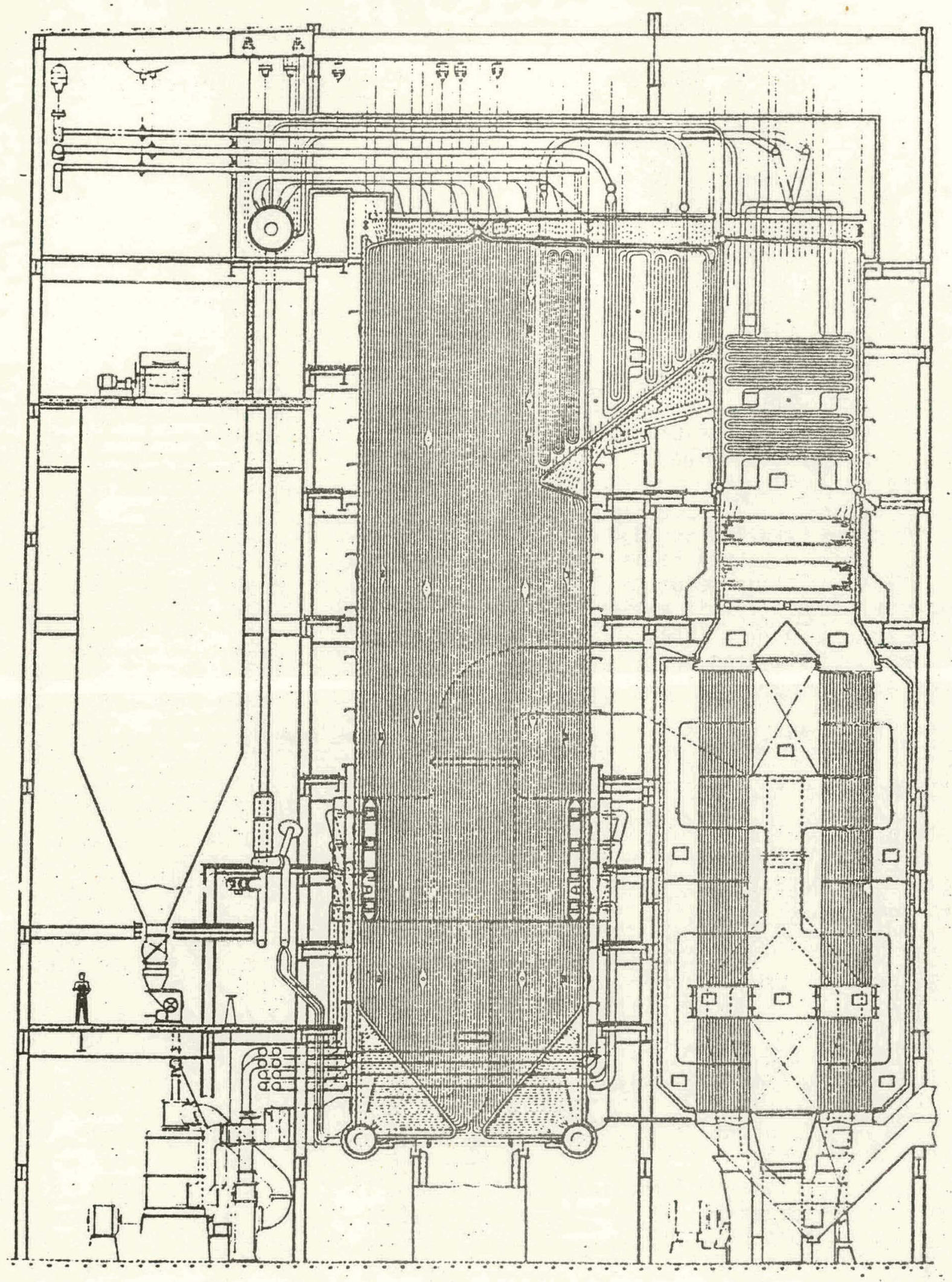

Figure 3: Vermilion Power Plant \#1 -- Boiler Arrangement 
TABLE 1. Zeigler Mine Coal Analysis -- Vermilion Power Plant MINERAL ANALYSIS OF ASH Percent Weight Ignited Basis

Silica, $\mathrm{SiO}_{2}$

Al umina, $\mathrm{Al}_{2} \mathrm{O}_{3}$

47.15

Titania, $\mathrm{TiO}_{2}$

22.88

1.08

Ferric oxide, $\mathrm{Fe}_{2} \mathrm{O}_{3}$

20.23

Lime, $\mathrm{CaO}$

2.53

Magnesia, MgO

0.71

Potassium oxide, $\mathrm{K}_{2} \mathrm{O}$

2.10

Sodium oxide, $\mathrm{Na}_{2} \mathrm{O}$

Sulfur trioxide, $\mathrm{SO}_{3}$

0.61

Phos. pentoxide, $\mathrm{P}_{2} \mathrm{O}_{5}$

1.47

Stontium Oxide, SrO

0.57

Barium Oxide, BaO

0.12

Manganese $\mathrm{Ox}$ ide, $\mathrm{Mn}_{2} \mathrm{O}_{3}$

0.06

Indetermi nerl

0.05

0.44

100.00

Alkalies as $\mathrm{Na}_{2} \mathrm{O}$

(Dry Coal Bașis)

Silica Value

0.23

Base: Acid Ratio

66.77

Fouling Index

0.37

Slagging Index

0.23

0.98

PROXIMATE ANALYSIS

ULIIMAIE ANALYSIS

\begin{tabular}{lccc} 
As Rec'd. & & Dry Basis & \\
\cline { 1 - 1 } Moisture & 13.34 & & $\%$ \\
Ash & 10.04 & & xxxxx \\
Volatile & 35.10 & & 40.59 \\
Fixed Carbon & 41.52 & & 47.91 \\
& 100.00 & 100.00
\end{tabular}

HHV Btu/1b. 10600

12232

Mo isture

Carbon

Hydrogen

Nitrogen

Chlorine

Sulfur

Ash

Oxyyen $\frac{\text { As } \operatorname{Rer} ' d \text {. }}{\%}$

13.34

61.74

4.36

0.91

0.12

2.30

10.04

7.19

$10 \overline{0.00}$
$\frac{\text { Dry Basis }}{\%}$
$x x x x x$
71.24
5.03
1.05
0.14
2.65
11.59
8.30
$10 \overline{0.00}$

\section{FIISION TFMPERATURE OF ASH}

Reducing

Initial Deformation, IT

Softening, ST

Softening, HT

Fluid, FT $2040^{\circ} \mathrm{F}$

$2250^{\circ} \mathrm{F}$

$2300^{\circ} \mathrm{F}$

$2480^{\circ} \mathrm{F}$ 
temperature and enthalpy) and the mass flow rates of all streams (both primary and secondary flows) until all operational specifications were met. Specific parameters for each component, e.g., turbine efficiency, were fixed by input, matching the rated Vermilion values when available, but otherwise taken as typical values. In this manner, typical performance parameters for individual components were calibrated to reflect the actual Vermilion \#1 plant.

Figure 4 is a schematic of the Vermilion power plant. Table 2 provides a comparison of calculated and actual surface areas for the Vermilion power plant. Table 3 consists of typical available operating data from the Vermilion station. Table 4 lists the state points defined by the schematic for $100 \%$ load. Comparisons between the actual and calculated surface areas in Table 2, actual and calculated state points in the Tables 3 and 4 show good agreement.

TABLE 2: Comparison Between Available and Calculated Surface Areas

Component

Furnace

Superheater \#1

$$
\# 2
$$$$
\text { \#3 }
$$

Reheater \#1

$$
\# 2
$$

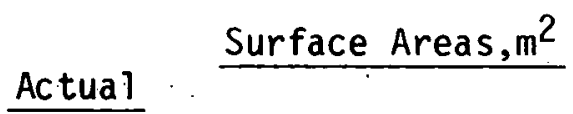

981

1017

1017

944

212

500

16025

1254

1254

210

275

172

219
Calculated

981

1035

1013

943

237

550

16005

1256

1261

Feedwater Heater \#1

\#2

$\# 3$

\#4 


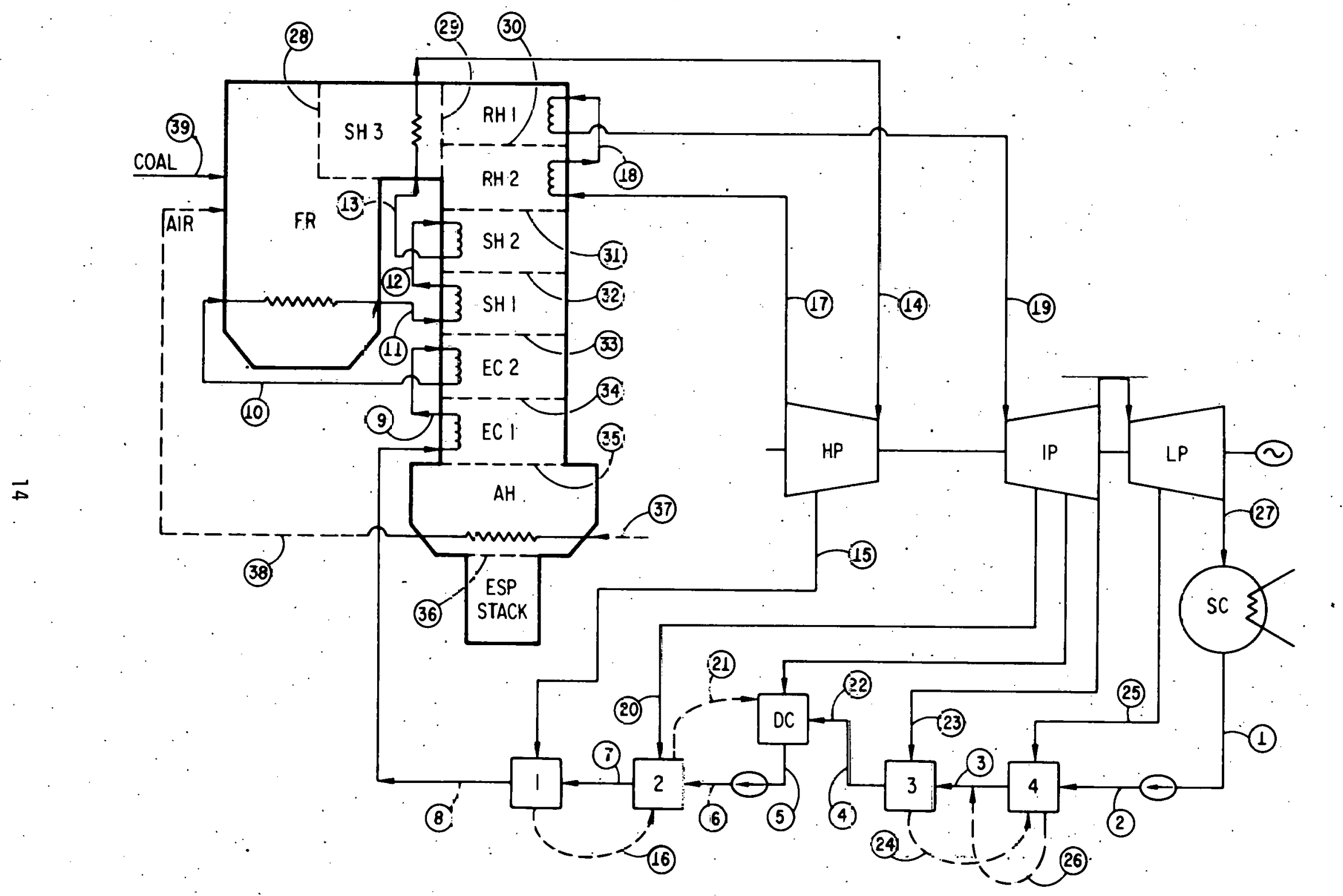

Figure 4: Vermilion Power Plant \#1 -- Schematic 
TABLE 3: Vermilion \#1 -- Available State Point Information

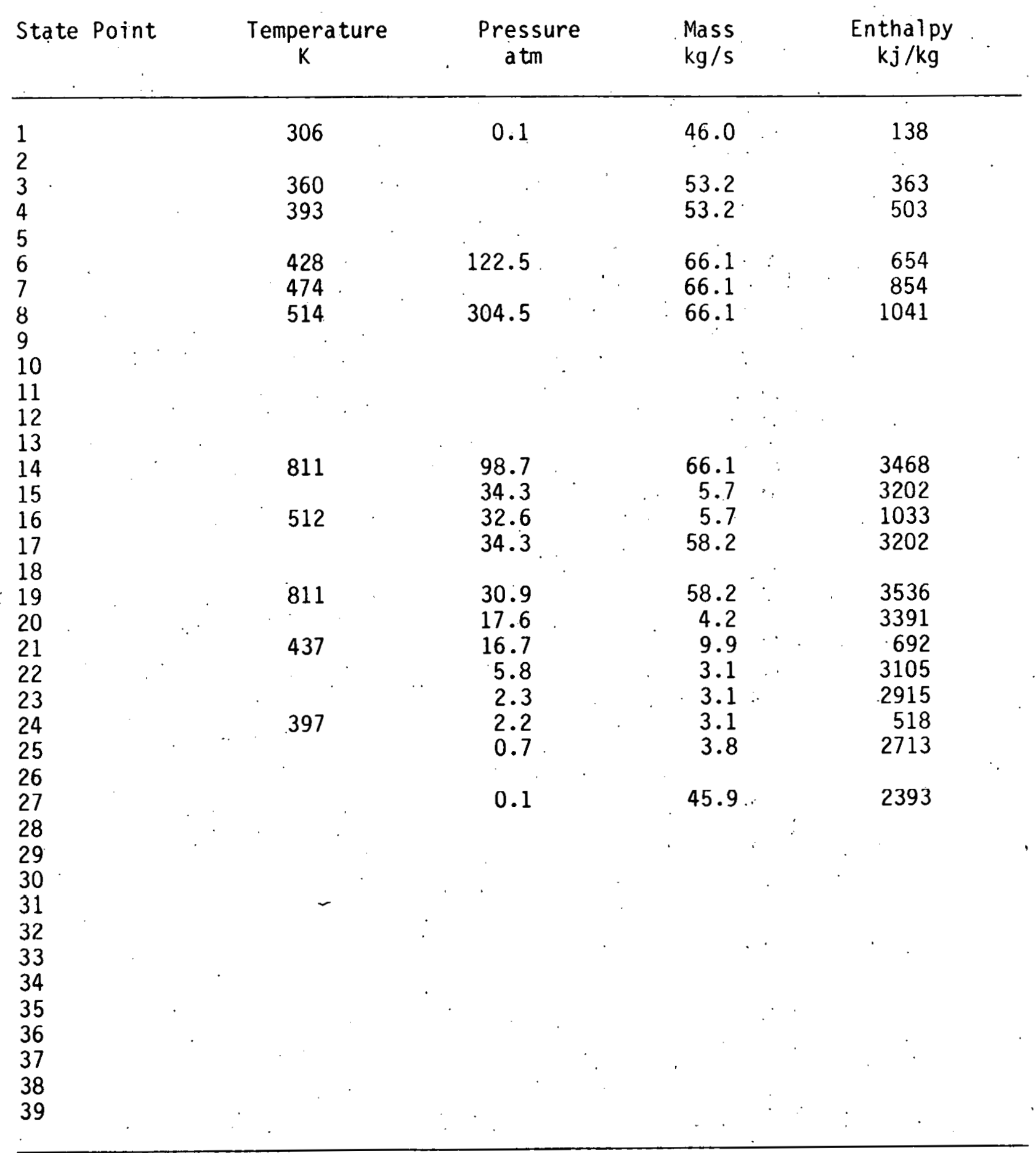


TABLE 4: Vermilion \#1 -- Calculated State Points

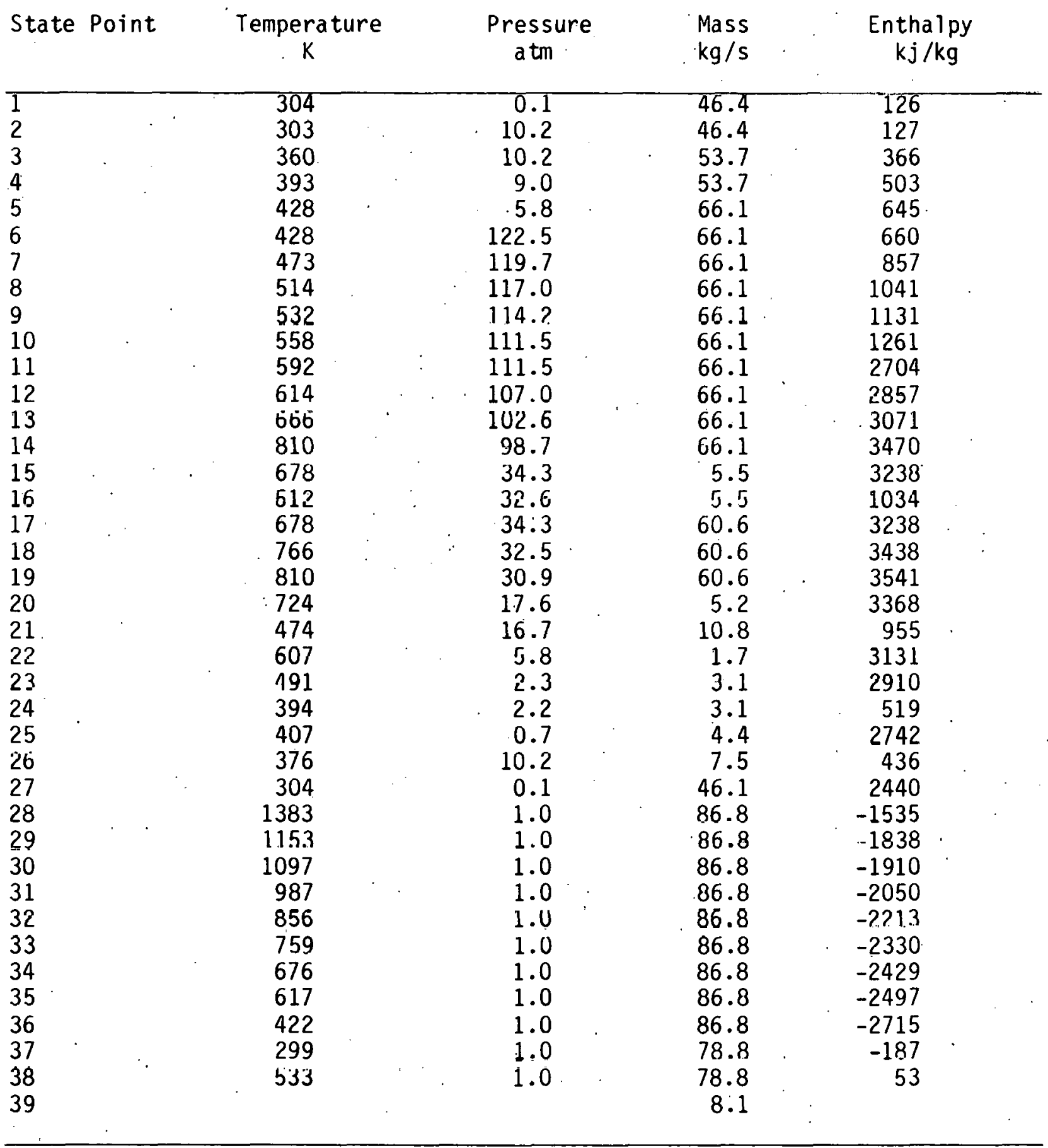




\section{A. Retrofit Constraints}

Retrofit design of the Vermilion \#1 plant began with the basic guideline that the conventional boiler should operate normally whether or not used in conjunction with the MHD topping cycle. Implicit in this guideline are the constraints (previously mentioned in Section II) which must be met regarding design and operational requirements or specifications: a maximum mass flow rate of gas flowing through the conventional boiler sections equal to a $10 \%$ overload, metal temperatures of steam/water heat transfer surfaces are less than $15^{\circ} \mathrm{F}(8 \mathrm{~K})$ higher than under normal operation, and a separate steam loop designed to utilize the heat from the MHD cooling system, without direct steam connections between the existing and new loops. In addition, the flue gas exit tempera-ture (dew point constraint) should remain as low as possible for full utili-zation of low-grade heat. Also, because the air heater of the existing steam generator will be used only to support secondary combustion of MHD gases, the amount of air necessary for this function is only $20 \%$ of the design mass flow rate of air during conventional operation. Thus, an additional heat exchanger should be installed downstream of the air heater to use the resulting increase in the amount of available energy in the flue gas stream.

Several special design requirements for the MHD topping cycle were im-. posed on this retrofit study. Most of these requirements were based on the work performed in support of the Engineering Test Facility (ETF) $[21,22]$. The combustion air is preheated to $1100^{\circ} \mathrm{F}(868 \mathrm{~K})$. The coal is dried to $5 \%$ moisture content. The combustor heat loss (absorbed by the cooling system) is assumed to be $8 \%$. Approximately $75 \%$ of the slag is removed in the combustor; the remainder travels with the gas stream. Of this $25 \%$ ash carryover, $60 \%$ is assumed to enter the existing furnace. Most of these particles will be of submicron size, having. formed from slag vapor, which condensed to submicron particles in the channel. [23]. Seed vapor condenses on these ash particles as well as on cool surfaces in the steam plants [24]. The MHD generator characteristics were established from a detailed study to determine a near-optimum 
channel design that characterized a typical channel for this power level: $12 \mathrm{~m}$ long, and peak magnetic field intensity of $6 \mathrm{~T}$. The channel and combustor cooling systems should operate on conderisate or feedwater from the new steam 10op. Water pressure in the channel cooling system should be no higher than 411 psig (2.8 $\mathrm{MPa}$ ) because flexible tubing will be required, and absolutely no boiling can be permitted. Pressure in the combustor cooling system should be specified to match the initial steam pressures at the turbines, with steam quality in the cooling system being as low as possible. A desirable objective, although it may be unnecessarily conservative, is to prohibit boiling in the water-cooled walls of the combustor.

Since the feedwater is largely heated in the combustor and channel cooling systems, plus the additional heat exchanger section in the existing boiler, the new steam turbine cycle can contain few (perhaps not any) feedwater heaters. (With constraints of no boiling and full utilization of the low-grade heat, the topping cycle adds significant new capacity to the system. This capacity may be increased further, to permit the use of feedwater heaters. No decision has yet been reached on this possibility since - this option has not been studied). The new steam turbine cycle condensate should be used for the additional economizer in the existing steam generator, again for the purpose of full utilization of the low grade heat. Finally, this new steam loop should provide, enough power to drive both the main compressors and those of the oxygen enrichment plant.

\section{B. Description of the MHD Retrofit Plant}

A retrofit design was developed for each of the two design options. In one, Configuration "A"., the combustion gas mass fiow is split to satisfy the maximum gas flow constraint through the conventional boiler, yet allow for all additional heating that might be required for full utilizaliun of the low grade heat. In this option, full utilization was to heat grade the existing boiler is obtained without establishing the size of the MHD topping cycle. The constraint on the maximum mass flow rate through the existing boiler is not a restriction on the topping cycle because the MHD gas is split into two parts: one part where the gas passes through the existing boiler and a second part where the gas passes through a new convective section for the new turbine 
train. Therefore, the new steam loop can be sized as to satisfy the steam quality constraint in the cooling flows of both the combustor and channel, using the low-grade heat as feedwater heating. In the second option, Configuration " $B$ ", the combustion gas follows a single path through both sections of the plant (no new convective section), with the mass flow rate through the conventional boiler (after secondary combustion) being set to the maximum allowed: $758,0001 \mathrm{~b} / \mathrm{hr}(95.5 \mathrm{~kg} / \mathrm{s})$. In this option, the size of the MHD steam loop is much reduced. No constraint is placed on the quality of the combustor cooling flow, although the zero steam quality is still maintained for the channel cooling flow. In this way, degradation of the available heat energy in the combustion gas flowing through the MHD train can be prevented and sufficient heat energy retained for full utilization of the existing boiler.

In both options, pulverized coal; fed from a lock hopper, is burned in the MHD combustor with $42 \%$ oxygen-enriched air (amount of oxygen in oxidizer by weight) at a pressure of $90 \mathrm{psig}(0.60 \mathrm{MPa})$. The oxidant is preheated to $1100^{\circ} \mathrm{F}(868 \mathrm{~K})$ in the Intermediate-Temperature Air Heater (ITAH) of the MHD plant. A portion of the oxidant is injected into the first stage of the combustor, from which $75 \%$ of the coal ash is separated. The balance of the oxidant and a concentrated water solution of the potassium seed material are injected into the second stage, to produce a combustion gas that is approximately $10 \%$ fuel rich, has a temperature of $4575^{\circ} \mathrm{F}(2800 \mathrm{~K})$, and contains 1 mass \% potassium. The heat loss from the combustor and nozzle is assumed to be $8 \%$ of the coal heating value, and this loss is recovered and used to heat the boiler feedwater.

After the gas accelerates to near Mach 1 in the nozzle, it flows through the MHD channel, which is located in a $6 \mathrm{~T}$ magnetic field, produced by a superconducting magnet. The gas has a relatively high electrical conductivity, because of the ionization of potassium atoms that results from. the high temperature. The electrical conductor moving through the magnetic field generates a calculated electrical potential of several thousand volts and power of $94 \mathrm{MW}$ (53 MW with configuration "B"). The current is drawn off through electrodes within the channel walls which make electrical contact with the gas. 
After being decelerated in a diffuser, the channel exhaust gases flow through the radiant boiler ( $\mathrm{NO}_{\mathrm{x}}$ decomposition furnace) of the retrofit system, the heat in the gas being used to produce high-pressure steam. Secondary air, which is preheated to $630^{\circ} \mathrm{F}(600 \mathrm{~K})$ in the plant's original air heater, is mixed with the fuel-rich gas near the exit of the MHD radiant boiler, producing a fuel-lean gas with a stoichiometric ratio of 1.05 . In addition to the boiling capacity, heat is also recovered for superheating and reheating steam.

The walls of the radiant boiler and the diffuser are comprised of boiler tubes, which are covered with a refractory liner to reduce metal attack through corrosion and erosion, resulting from contact with the slag-laden alkaline gas, and to limit the heat transfer rate. The latter consideration arises from the need to 1 imit the gas c00ling rate to 1 ess than $400^{\circ} \mathrm{F} / \mathrm{s}(222$ $\mathrm{K} / \mathrm{S})$, in order to facilitate the decomposition of $\mathrm{NO}_{\mathrm{X}}$, which is present in high concentrations in the channel exhaust gases. After an initial break-in period the refractory lined walls will be coated with slag.

In Retrofit Configuration "A", shown in Figure 5, the gas from the MHD topping. train is split into two flows. Approximately $210 \mathrm{lb} / \mathrm{s}(95 \mathrm{~kg} / \mathrm{s})$ flows into the conventional system and the balance, $145 \mathrm{lb} / \mathrm{s}(66 \mathrm{~kg} / \mathrm{s})$, flows into the separate MHD steam system. In the latter, heat is extracted to produce steam, preheat primary combustion oxidant, heat boiler feedwater, and dry coal to less than $5 \%$ moisture. The other stream of combustion gas flows through a horizontal, water-cooled duct and, at $3050^{\circ} \mathrm{F} \cdot(1950 \mathrm{~K})$, enters the conventional furnace at a location near the existing coal burners. Small amounts of liquid seed deposits will form on the lower furnace wall. In order to maintain effective heat transfer over the entire furnace volume, wall hlowers must be used in the cooler upper parts of the wall, where solid seed deposits will form. Seed containing some slag will be removed from the bottom nf the furnace; hence, some modification of the bottom of the furnace is necessary to accommodate this function.

The temperature of the gas entering the pendant superheaters at the top of the furnace must be below the freezing point of $\mathrm{K}_{2} \mathrm{SO}_{4}$. Accordingly, the remaining seed will be entrained solid particulate material and the resultant deposits of solid particles can be effectively removed by soot blowers. 


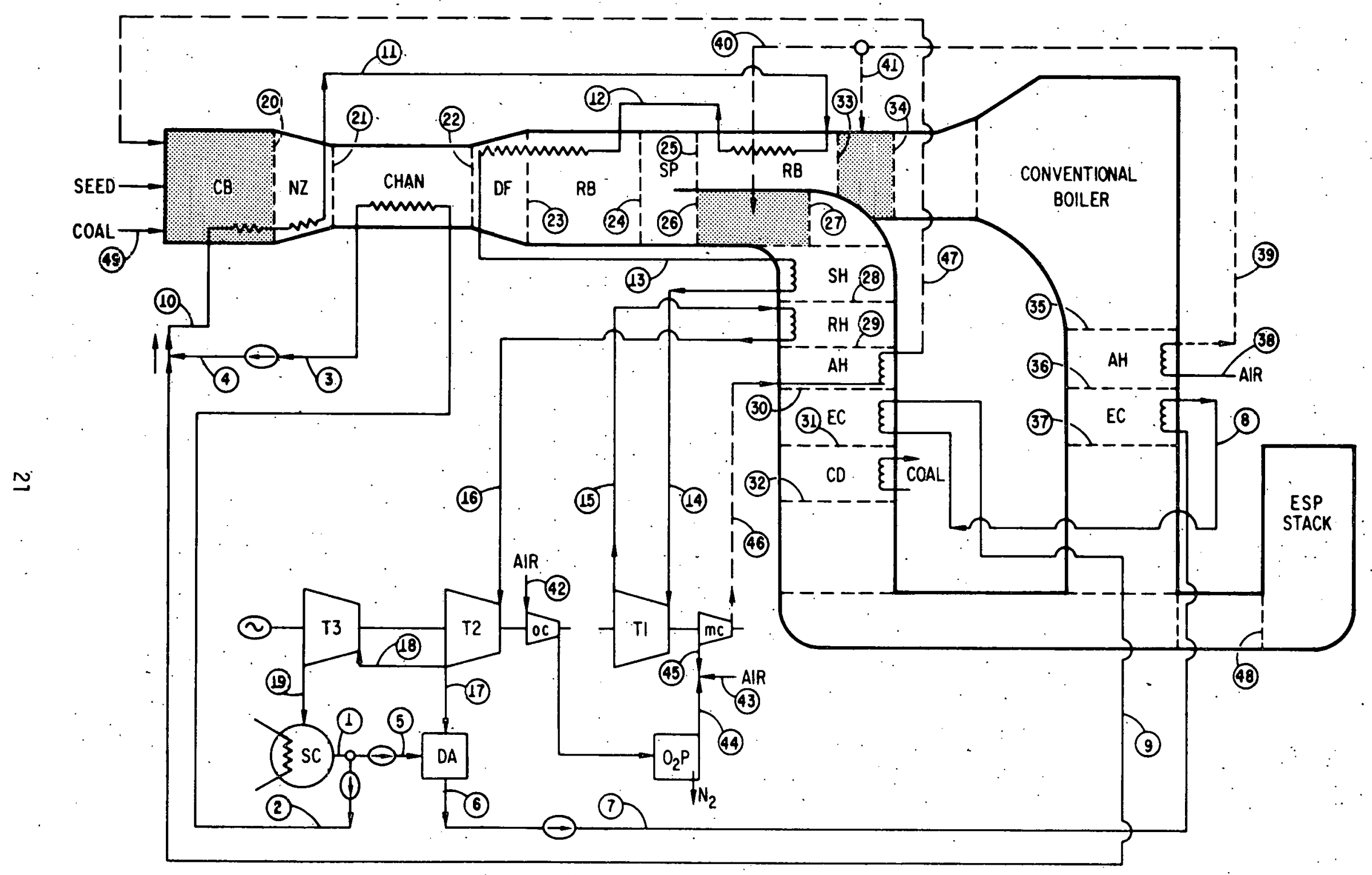

Figure 5: Retrofit Configuration. "A" -- Schematic 
Splitting the mass flow of the gas into two sections allows full utilization of all low-grade heat, yet still meets the constraint of not permitting boiling in the channel or combustor. Additional MHD heating capacity is provided without a deterioration of the heat to be used through the conventional forced-circulation, once through boiler. As shown in Figure 5, two boiling sections are provided for the MHD steam 10op, one in the main MHD gas stream and one in the additional MHD heating section. No constraint was imposed on the distribution of heating between these two boiling sections. Therefore, with Retrofit Design " $A$ ", it is possible to begin with zero boiling in the combustor, obtain approximately $78 \%$ evaporative load in the "additional" boiler section and then obtain the remainder of evaporative load in the "main MHD" boiler, using the available low-grade heat without violating the boiling requirements in either the combustor or MHD channel.

The second retrofit. design, shown in Figure 6, has the feature of a lower mass flow rate of gas (constrained to the design mass flow rate plus $10 \%$ ), so that additional stack capability is not required. However, constraining the combustor cooling water to $0 \%$ steam quality would result in significant deterioration of the heat available for the conventional boiler section because the boiling (hence superheating) requirements would be corresponding reduced, and hence, the turbine would be derated. By allowing 33\% steam boiling in the combustor conling water, a heat balance was calculatcd for Retrofit Configuration "B".

It should be noted, here, that research is in progress in the design of velox combustors with up to $100 \%$ hoiling in their cooling systems $[25,26,27]$. Contemporary research tends to support the conclusion that prohibiting boiling in the combustor is an unnecessarily conservative design constraint.

The configuration of the MHD steam cycle is similar in both retrofit design options. As indicated in Figures 5 and 6 , the MHD steam system contains three turbines: a high-pressure turbine supplying $27 \mathrm{MW}$ for the primary oxidant compressor in Configuration "A" (16 MW in Configuration "B"), and a pair of turbines operating with intermediate-pressure steam to produce $21 \mathrm{MW}$ for the enrichment plant compressor and 74 MW of saleable electrical power 


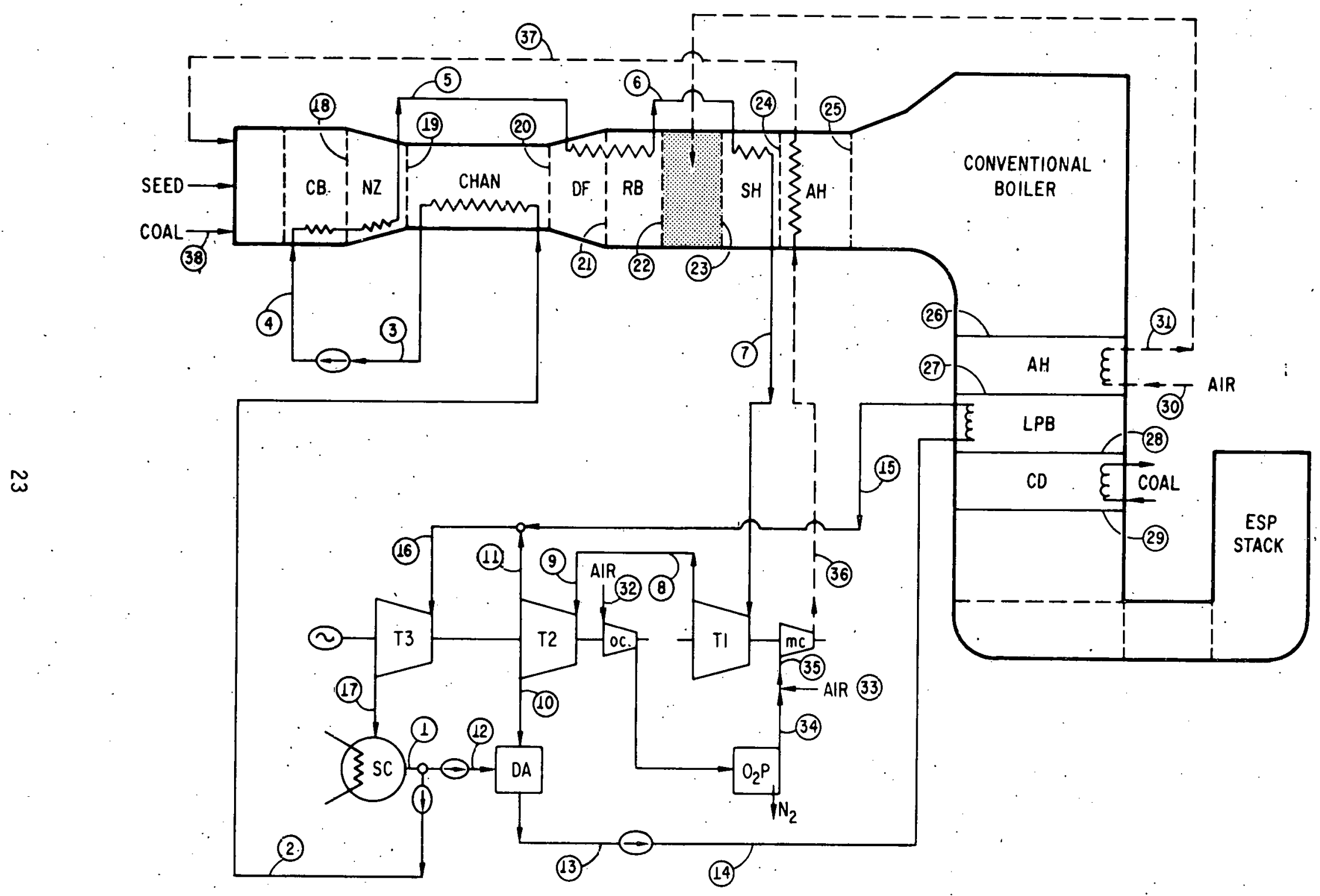

Figure 6: Retrofit Configuration "B" ... Schematic 
with Configuration "A" $(12 \mathrm{MW}$ and $8 \mathrm{MW}$, in the same order, for Configuration "B"). Part of the low-pressure steam condensate is used to cool the channel and the balance is pumped, at high pressure, to economizers in the conventional section and the MHD bypass system. These flows are then mixed and pumped to the cooling systems of the primary combustor and nozzle, then to the boiler. Because there is enough heat from the combustor and channel for heating boiler water; the retrofit steam plant has only a deaerator and no feedwater heaters. Except for the portion of the retrofit feedwater that passes through the new economizer of the conventional system; there are no steam/water heat transfer surfaces between either of the MHD retrofit. options and the conventional plant. (There is no direct mixing of steam/water between topping and bottoming cycles.)

The overall results for the two retrofit options, compared to the Vermilion plant, are listed in Table 5: The calculated thermal efficiencies for both designs clearly show that Retrofit Configuration " $A$ " is superior to Configuration "B", and both cases show a marked increase over the existing efficiency. The improvement is $14.2 \%$ for Configuration " $A$ ", (increasing to $38.1 \%$ frull $33.7 \%$ ), and only $6.1 \%$ for Configuration "B" (to $35.9 \%$ from $33.7 \%)$. These increases in efficiency correspond to improvements in net power produced of $260 \%$ for Configuration "A". [which produced 215 MW (electrical) vs 67 previously], and of $96.7 \%$ for Configuration "B" [132 MW (electrical) vs 67]. Both retrofit options demon-strate a significant improvement in coal utilization.

Detalled results of state points are presented in Tables 6 and 7 . (The state points are identified in the corresponding figures for the two design options). Changes in maximum metal temperatures that result when the conventional sections are combined with the MHD topping cycle did not exceed $11^{\circ} \mathrm{F}(6$ K) for the steam-water tubes and $90^{\circ} \mathrm{F}\left(50^{\circ} \mathrm{K}\right)$ for the low temperature air heater. Estimated ranges for auxiliary power requirements are presented in Table 8. 
TABLE 5: Summary of Results

Vermilion Case A. Case B

\begin{tabular}{|c|c|c|c|}
\hline $\begin{array}{l}\text { PLANT EFFICIENCY } \\
\%\end{array}$ & 33.7 & $\begin{array}{c}38.1 \\
(+13 \%)\end{array}$ & $\begin{array}{l}35.9 \\
(+6.7 \%)\end{array}$ \\
\hline $\begin{array}{c}\text { NET POWER PRODUCED } \\
\text { MW }\end{array}$ & 66.9 & $\begin{array}{l}245: 0 \\
(+266 \%)\end{array}$ & $\begin{array}{l}131.6 \\
(+96.7 \%)\end{array}$ \\
\hline $\begin{array}{c}\text { GAS MASS FLOW } \\
\mathrm{kg} / \mathrm{s}\end{array}$ & 86.8 & $\begin{array}{l}167.8 \\
(+93 \%)\end{array}$ & $\begin{array}{l}95 . .5 \\
(+10.0 \%)\end{array}$ \\
\hline $\begin{array}{l}\text { COAL MASS FLOW } \\
\mathrm{kg} / \mathrm{s}\end{array}$ & 8.06 & $\begin{array}{l}26.1 \\
(+224 \%)\end{array}$ & $\begin{array}{l}14.9 \\
(+84.5 \%)\end{array}$ \\
\hline
\end{tabular}

GROSS POWER PROD.

$\begin{array}{lllllll}\text { MW. } & 71.9 & & & & & \end{array}$

AUXILIARY POWER

REQ'D, MW $\quad 5.04 \quad 10.6 \quad: \quad 7.1$

MAIN COMPRESSOR

POWER REQ'D, MW

$\begin{array}{ll}--- & 28.0\end{array}$

15.7

$0_{2}$ PLANT POWER REQ'D, MW

$-\infty$

21.7

12.4

EXCESS MHD TURBINE CAPACITY, MW

86.5

14.1

MHD CHANNEL POWER

MW

--.-

97.0

52.5 
TABLE 6: Retrofit "A".--Calculated State Points

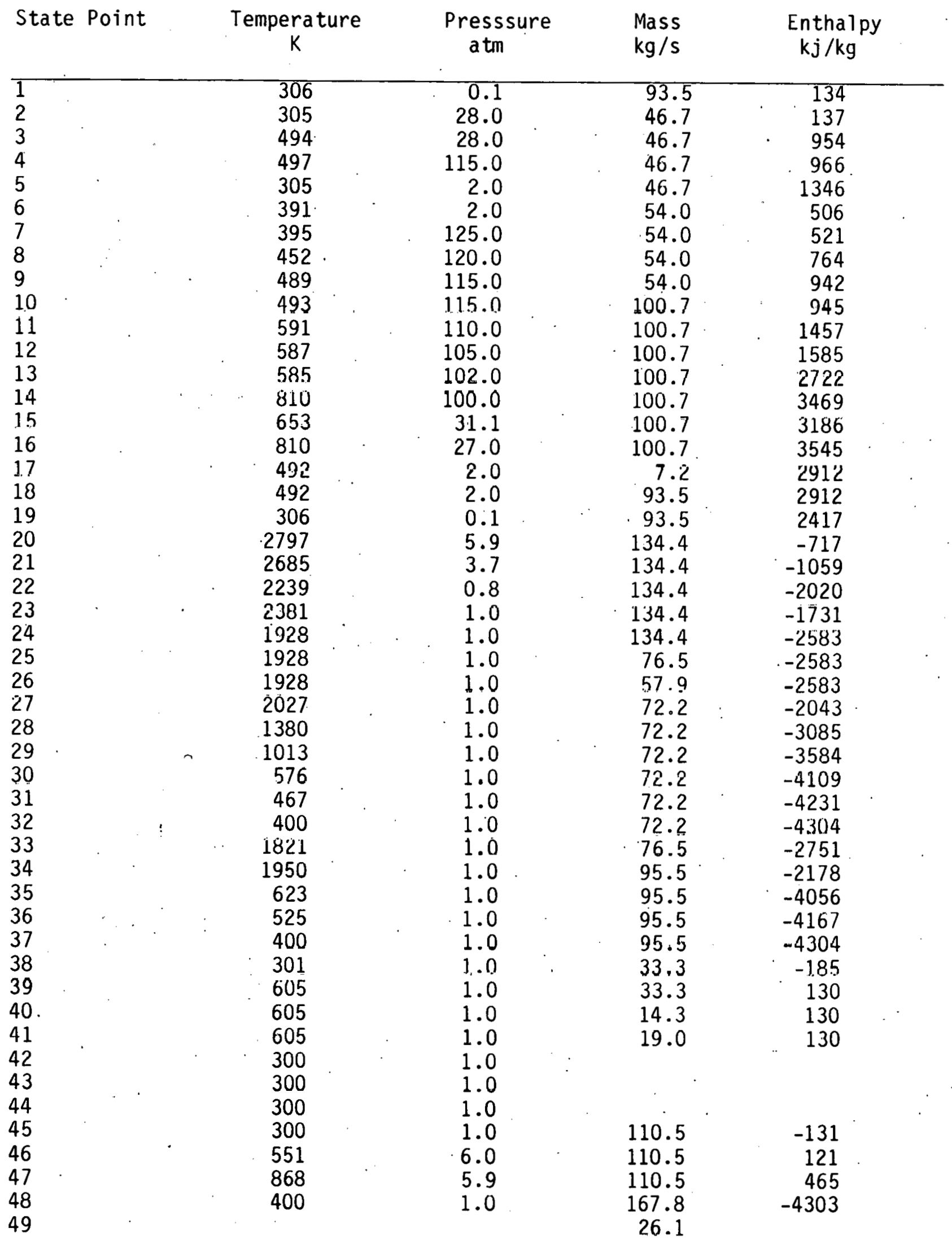


TABLE 7: Retrofit "B" -- Calculated State Points

\begin{tabular}{|c|c|c|c|c|c|}
\hline State & Point & $\underset{K}{\text { Temperature }}$ & $\begin{array}{l}\text { Presssure } \\
\text { atm }\end{array}$ & $\begin{array}{l}\text { Mass } \\
\mathrm{kg} / \mathrm{s}\end{array}$ & $\begin{array}{c}\text { Enthalpy } \\
\mathrm{kj} / \mathrm{kg}\end{array}$ \\
\hline $\begin{array}{l}1 \\
2 \\
3 \\
4 \\
5 \\
6 \\
7 \\
8 \\
9 \\
10 \\
11 \\
12 \\
13 \\
14 \\
15 \\
16 \\
17 \\
18 \\
19 \\
20 \\
21 \\
22 \\
23 \\
24 \\
25 \\
26 \\
27 \\
28 \\
29 \\
30 \\
31 \\
32 \\
33 \\
34 \\
35 \\
36 \\
37 \\
38 \\
\end{array}$ & . & $\begin{array}{r}306 \\
305 \\
49,8 \\
501 \\
591 \\
585 \\
810 \\
544 \\
544 \\
391 \\
391 \\
305 \\
391 \\
391 \\
391 \\
391 \\
306 \\
2795 \\
2685 \\
2219 \\
2363 \\
2181 \\
2223 \\
2080 \\
1950 \\
623 \\
565 \\
429 \\
400 \\
301 \\
618 \\
300 \\
300 \\
300 \\
300 \\
548 \\
868 \\
\end{array}$ & $\begin{array}{r}0.1 \\
28.0 \\
28.0 \\
115.0 \\
110.0 \\
102.0 \\
100.0 \\
11.7 \\
11.7 \\
2.0 \\
2.0 \\
2.0 \\
2.0 \\
2.3 \\
2.0 \\
2.0 \\
0.1 \\
5.8 \\
3.6 \\
0.8 \\
1.0 \\
1.0 \\
1.0 \\
1.0 \\
1.0 \\
1.0 \\
1.0 \\
1.0 \\
1.0 \\
1.0 \\
1.0 \\
1.0 \\
1.0 \\
1.0 \\
1.0 \\
5.9 \\
5.8\end{array}$ & $\begin{array}{r}59.4 \\
33.2 \\
33.2 \\
33.2 \\
33.2 \\
33.2 \\
33.2 \\
33.2 \\
33.2 \\
4.5 \\
28.7 \\
26.2 \\
30.7 \\
30.7 \\
30.7 \\
59.4 \\
59.4 \\
76.5 \\
76.5 \\
76.5 \\
76.5 \\
76.5 \\
95.5 \\
95.5 \\
95.5 \\
95.5 \\
95.5 \\
95.5 \\
95.5 \\
19.0 \\
19.0\end{array}$ & $\begin{array}{r}134 \\
137 \\
971 \\
983 \\
1865 \\
2722 \\
3469 \\
2988 \\
2988 \\
2668 \\
2668 \\
1346 \\
506 \\
506 \\
975 \\
1794 \\
1521 \\
-7174 \\
-1059 \\
-2061 \\
-1773 \\
-2145 \\
-1690 \\
-1950 \\
-2178 \\
-4056 \\
-4122 \\
-4273 \\
-4304 \\
-185 \\
143 \\
\therefore \\
\because \\
- \\
-131 \\
118 \\
465\end{array}$ \\
\hline
\end{tabular}


TABLE 8: Power Consumption of Auxiliary Equipment

\begin{tabular}{|c|c|c|c|c|}
\hline I tems & & $\begin{array}{l}\text { Separate } \\
\text { Operation }\end{array}$ & $\begin{array}{l}\text { Joint } \\
\text { Operation } \\
\text { (Case "A") }\end{array}$ & $\begin{array}{l}\text { Joint } \\
\text { Operation } \\
\text { (Case "B") }\end{array}$ \\
\hline Fuel Supply & $\% * / M W$ & $\frac{0.06}{0.043}$ & $\frac{0.05}{0.12}$ & $\frac{0.04}{0.07}$ \\
\hline Coal Pulverization & $\% / \mathrm{MW}$ & $\frac{6.10}{0.79}$ & $\frac{0.85}{2.04}$ & $\frac{0.85}{1.37}$ \\
\hline Hydraul ir. Ash Di spnssạ] & $\% / \mathrm{MW}$ & $\frac{0.35}{0.25}$ & $\frac{0.31}{0.75}$ & $\frac{0.27}{0.45}$ \\
\hline Draft (forced \& induced) & $\% / \mathrm{MW}$ & $\frac{1.45}{1.04}$ & $\frac{0.60}{1.44}$ & $\frac{0.48}{0.80}$ \\
\hline Water Treatment & $\% / \mathrm{MW}$ & $\frac{0.06}{0.043}$ & $\frac{0.06}{0.14}$ & $\frac{0.05}{0.08}$ \\
\hline Feed Water Pumps & $\% / \mathrm{MW}$ & $\frac{2.50}{1.80}$ & $\frac{0.8}{1.93}$ & $\frac{0.8}{1.33}$ \\
\hline Circulating Water Pumps & $\% / \mathrm{MW}$ & $\frac{1.20}{0.86}$ & $\frac{0.85}{2.12}$ & $\frac{0.84}{1.40}$ \\
\hline 0thers & x/MW & $\frac{0.30}{0.215}$ & $\frac{0.40}{0.95}$ & $\frac{0.30}{0.50}$ \\
\hline Total & $\% / \mathrm{MW}$ & $\frac{7.02}{5.04}$ & $\frac{3.69}{9.49}$ & $\frac{3.53}{6.00}$ \\
\hline
\end{tabular}

* $\%$ of Gross Power Production 
C. Distinguishing: Features of Retrofit Design.

Two significant modifications that are necessary to accommodate the retrofit application effectively: into the MHD power plant concept were identified. Previous MHD studies emphasized either one steam turbine train or a separate turbine train for the compressor drive only. These ideas could not be implemented in this retrofit application, because of the objective of not intruding on the integrity of the existing turbine system. Therefore, it was. necessary to have a.t least two separate steam loop.s. However, the: system could not be balanced and meet all operating limitations if the second steam loop was. sized to supply compressor power only. [typically, when two separate turbine trains are specified for MHD systems (e.g., ETF), the second train is used to supply compressor power only]; therefore it was necessary to design. for additional electrical capacity to be extracted from the new steam loop. Because the cooling train for the MHD: topping cycle has an abundance of: lowgrade heat, no feedwater heaters were needed for the new steam loop.

Another distinguishing: feature of the ANL retrofit design is the way: in which the gas path is merged with the existing furnace. The duct between the MHD train and the existing furnace is actually a duct/boiler combination, in order to avoid developing a special design for a high-temperature duct. The retrofit design introduces the gas as close to the existing burners as is physically feasible, and at state points close to existing state points, in order to maximize utilization of the heat transfer surface area in the: furnace. The seed will be in the form of a vapor when introduced into the furnace but will solidify before reaching the first superheater tubes. Much: of: the seed will follow the gas path and will not deposit on the furnace walls. Preliminary calculations [28] indicate that $88 \%$ of the seed and ash which enters the furnace will deposit throughout the steam generator system (see Table 9). During joint operation, the seed/ash deposition rate will be different in both magnitude and distribution from the ash deposition rate resulting from conventional operation. Modified soot blowers and the ESP. should be sufficient for adjustment to both modes of operation. However, the additional ESP, or new baghouse must accommodate the higher particle loading resulting from particles dislodged during soot blowing. 
TABLE 9: Ca:culated Particle Deposition in Conventional Boiler Air Case "A"

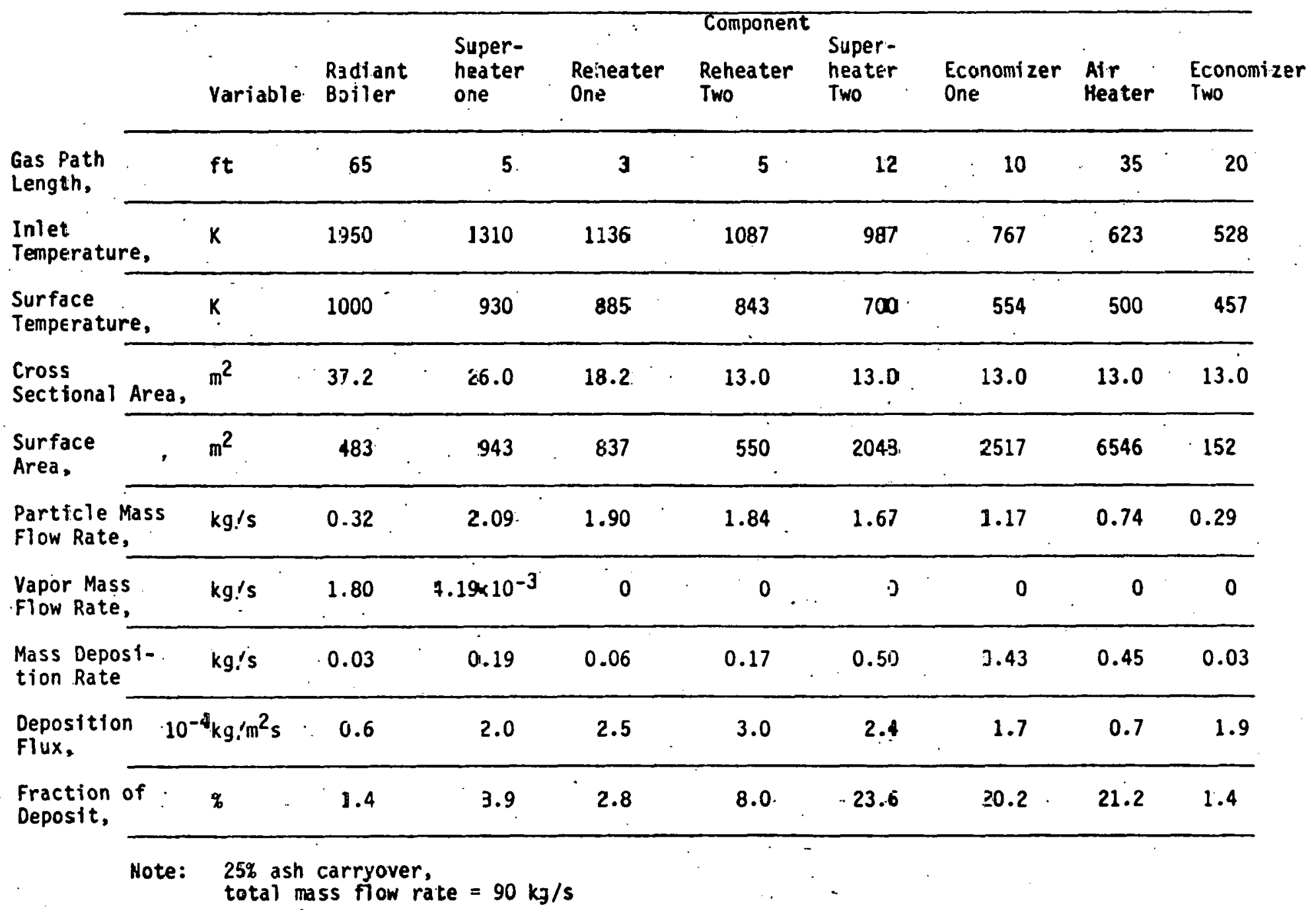


The fact that the seed and ash particles are solid at the flue gas temperatures in convective section of the boiler allows an MHD retrofit to be recommended for use in applications for most types of fossil-fired power plants. With the retrofit designs developed, the flame temperature in the existing boiler and the temperature of the combustion gas leaving the furnace can be adjusted so that they are equal to the corresponding design flames temperatures for many fossil fuels. Because of the separate compressor-steam turbine drive loop, the MHD topping cycle can be designed to use the amount of cooling water available from the MHD combustor; channel, and diffuser; thus integrity of the turbine train for the existing power plant need not be imparired.

\section{Modifications to the Existing Boiler}

1. The air duct from the existing afr heater would be modified so that the heated air could be directed to the secondary air registers in the. MHD plant during combined-cycle operation.

2. The burner area of the existing boiler would be modified to permit the introduction of combustion gas from the MHD plant at that height. The burners would operate unchanged for separate operation. The furnace bottom would be modified to handle liquid seed and slag during joint operation.

3. A low-pressure economizer would be added downstream of the existing air heater. (Under conventional-cycle operation, the low-pressure economizer (or low-pressure boiler) would not be used and the air heater would be used in the pre-retrofit manner).

4. Because of the higher small particle loading, an ESP of additional capacity, or a new baghouse system would be installed.

5. A new stack will be required if Boiler \#2 operates at the same time as the MHD retrofit of Boiler $\# 1$. 


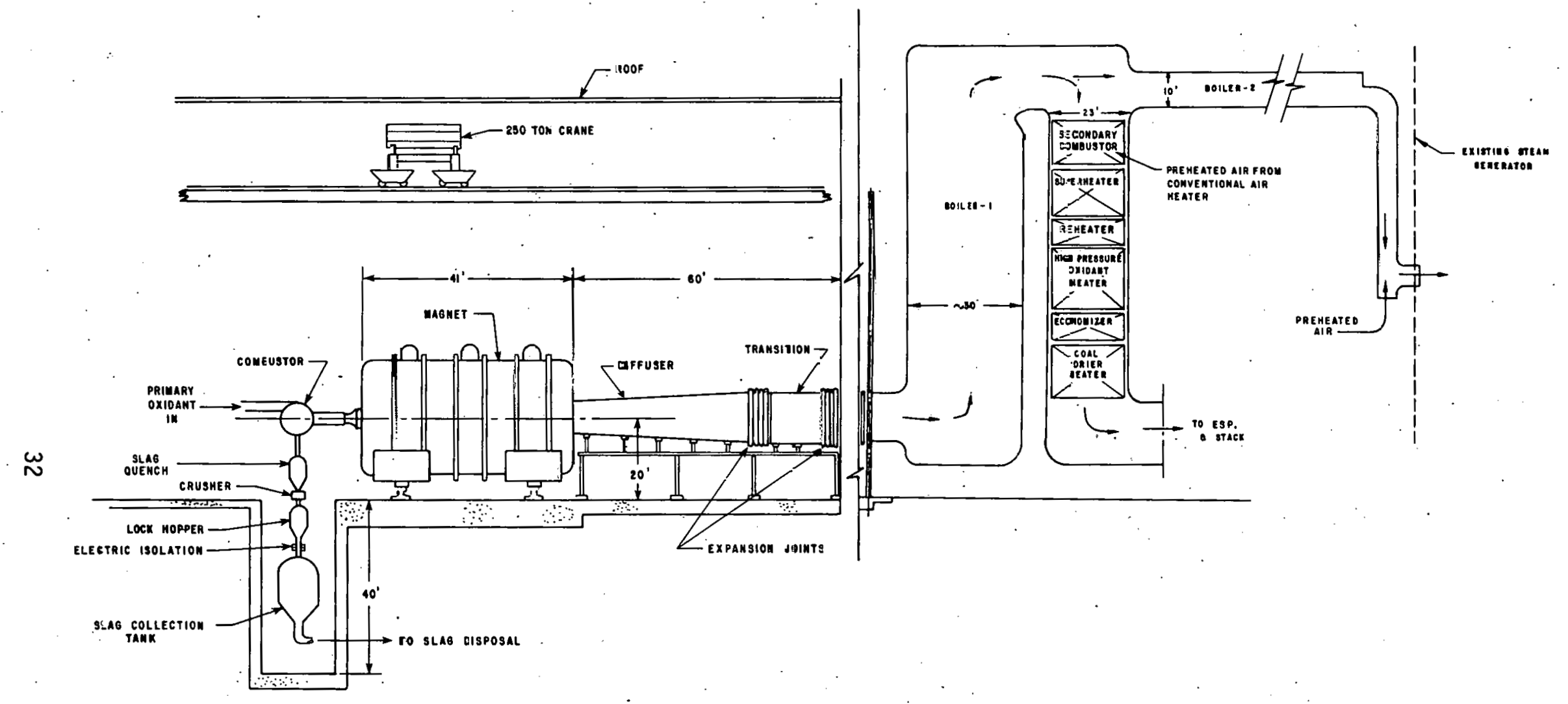

Figure 7: Vermilion Retrofit -- E'elation View 
E. New Components to be Added for Retrofit

1. The MHD topping train will consist of a combustor, nozzle, channel, and diffuser. (Refer to Figure 7, the elevation view of the retrofit plant). The combustor is a two-stage unit, the first stage of which is a modified cyclone-type combustor operating fuel-rich in the temperature range of $3600-3800^{\circ} \mathrm{F}(2255-2370 \mathrm{~K})$. Approximately $75 \%$ of the coal ash is rejected as liquid slag. In the second stage, enough oxidant is added to raise the oxygen-fuel ratio to approximately $85 \%$ of the theoretical stoichiometry, and seed material, $\mathrm{K}_{2} \mathrm{CO}_{3}$, is then injected. Such combustors are being developed by industry for the MHD program. Units with $20 \mathrm{MW}$ (therma1) rating have been tested successfully and a $50 \mathrm{MW}$ (thermnal) combustor is being designed [29]. A used $10 \mathrm{MW}$ (thermal) unit is installed in a test facility at Argonne. The 620-MW (thermal) combustor required for the retrofit would have a first stage roughiy $6 \mathrm{ft}(1.8 \mathrm{~m})$ in ID and $9 \mathrm{ft}(2.7 \mathrm{~m})$ in length. The second stage, at right angles to the axis of the first stage, would be approximately $3 \mathrm{ft}(0.9$ $\mathrm{m})$ in ID by $8 \mathrm{ft}(2.4 \mathrm{~m})$ in length. The temperature range of the combustion gases leaving the second stage is $4600-4800^{\circ} \mathrm{F}(2800-2910 \mathrm{~K})$.

The nozzle, where the combustion gas accelerates, is constructed of watercooled metal walls. This component is $2 \mathrm{ft}(0.6 \mathrm{~m})$ long and has a throat diameter of $3 \mathrm{ft}(0.9 \mathrm{~m})$.

The MHD channel is comprised of water-cooled electrodes. separated by refractory insulators. In addition to providing electrical separation, the insulation insures that the electrodes are coated with a thin film of slag, which protects them from erosion and mitigates the effects of arcs. The channel is $42 \mathrm{ft}(12 \mathrm{~m})$ long and square in cross-section, $3 \mathrm{ft}(0.9 \mathrm{~m})$ on a side at the inlet and $4 \mathrm{ft}(1.2 \mathrm{~m})$ at the outlet.

The diffuser decelerates the gas leaving the channel to an outlet velocity of $400 \mathrm{ft} / \mathrm{s}(122 \mathrm{~m} / \mathrm{s})$ and serves to convert the major portion of the kinetic energy to pressure head. This duct will be $58 \mathrm{ft}(18 \mathrm{~m})$ long, expanding at a 2.5 degree half angle from the channel outlet dimensions to the 6 by $6 \mathrm{ft}(1.8$ by $1.8 \mathrm{~m}$ ) inlet of the retrofit radiant boiler. The diffuser will be made up of refractory-coated, water-cooled walls that are part of the boiler circuit. 
2. The cryogenic superconducting magnet provides a 6 T (60,000-gauss) field for the MHD channel. A cryogenic unit supplying liquid helium at $-453^{\circ} \mathrm{F}$ $(4 \mathrm{~K})$, and an electrical energizing unit are associated with this magnet. An Argonne-built superconducting magnet has operated successfully with.a $10 \mathrm{MW}$ (thermal) MHD channel, and a similar magnet for a $50 \mathrm{MW}$ (thermal) channel has been successfully tested.

3. The MHD retrofit boiler (the Heat Recovery-Seed Recovery system, or HRSR) is similar to a conventional steam plant with forced water circulation consisting of a radiant boiler, secondary furnace, convective steam superheater and reheater, pressurized air heater, and economizer. The radiant boiler after the diffuser must provide residence time long enough $(2 \mathrm{sec})$ for the $\mathrm{NU}_{\mathrm{x}}$ in the channel exhaust gas to decompose to environmentally acceptable levels. To reduce the heat transfer rate somewhat, and to prevent erosion of the metal tubes by the reducing gases, the walls of the boiler are refractory lined. The gas leaving the diffuser is fuel-rich, hence, additional air is injected before entering the secondary furnace to complete combustion. The gas also contains $\mathrm{K}_{2} \mathrm{SO}_{4}$ in vapor phase, which has the potential for causing severe fouling of convective heat exchangers when it condenses. In the most critical fouling regime, where the gas is only 100 to $200^{\circ} \mathrm{F}$ (55 to $110 \mathrm{~K}$ ) above the melting point of the seed $\left(1950^{\circ} \mathrm{F}\right.$ or $\left.1340 \mathrm{~K}\right)$, convective surfaces will be widely spaced, and there will be numerous soot blowers. The retrofit oxidant heater (the Intermediate-Temperature Air Heater, ITAH) will preheat pressurized oxidant to approximately $1100^{\circ} \mathrm{F}(868 \mathrm{~K})$ for the primary combustor.

4. An ESP will be installed to remove particles, which are primarily $\mathrm{K}_{2} \mathrm{SO}_{4}$, from the effluent of the retrofit steam plant.

5. An induced-draft fan and a separate stack (for Configuration "A" only) will be installed.

6. An air enrichment plant will be located on site, to provide an oxidant with $42 \% \cdot \mathrm{O}_{2}$ for the MHD combustor. The plant selected is the energyefficient Lodepro process [30], which is used commercially in Europe. The energy for this plant is equivalent to 20 to $25 \%$ of the MHD channel output, and is obtained from a steam-driven compressor in the retrofit plant. 
7. Coal drying equipment is needed for the MHD plant to permit higher plasma temperature and, hence, electrical conductivity of the combustion gas. The coal moisture should be reduced to $3-5 \%$. Heat for this operation will be obtained by transfer of heat from the low temperature combustion gas or steam. In addition, the MHD retrofit will add separate coal preparation and feeding systems. These will include facilities for unloading, handling, and storing raw coal, pulverizers for preparing -200 mesh coal, and protected storage equipment for the dried pulverized coal. The feed system will consist of lock hoppers and pneumatic conveyors for injecting the coal into the first stage of the MHD combustor.

There will also be a system for feeding seed into the second stage of the combustor. It will include unloading and handling equipment, protected storage silos for the hydroscopic $\mathrm{K}_{2} \mathrm{CO}_{3}$, mixers for blending recycled seed material, and a lock hopper and injection system for feeding the blended seed into the combustor.

8. The retrofit steam turbine-generator system will consist of three turbines driving the compressors at the oxygen plant and primary oxidant, and an electrical generator. The air compressor for the enrichment plant will be constant speed, and the main oxidant compressor will be variable speed.

9. Additional cooling tower capacity will be added (perhaps, for configuration " $A$ " only) to handle the higher power levels of the combined plant.

10. Separatc facilities will be added to handle the slag and seed discharged from both the MHD and conventional plant. Water-soluble seed material will be separated from the ash and shipped off-site for processing.

11. Separate electrical transformers and switchgear will be provided. Inverters will be installed to convert the direct current supplied by the MHD generator to al ternating current.

12. New buildings will be provided to house the retrofit components, as indicated in Figure 8 . (Note that there is insufficient room at the Vermilion site to locate the MHD buildings adjacent to Boiler \#1 without relocating the 


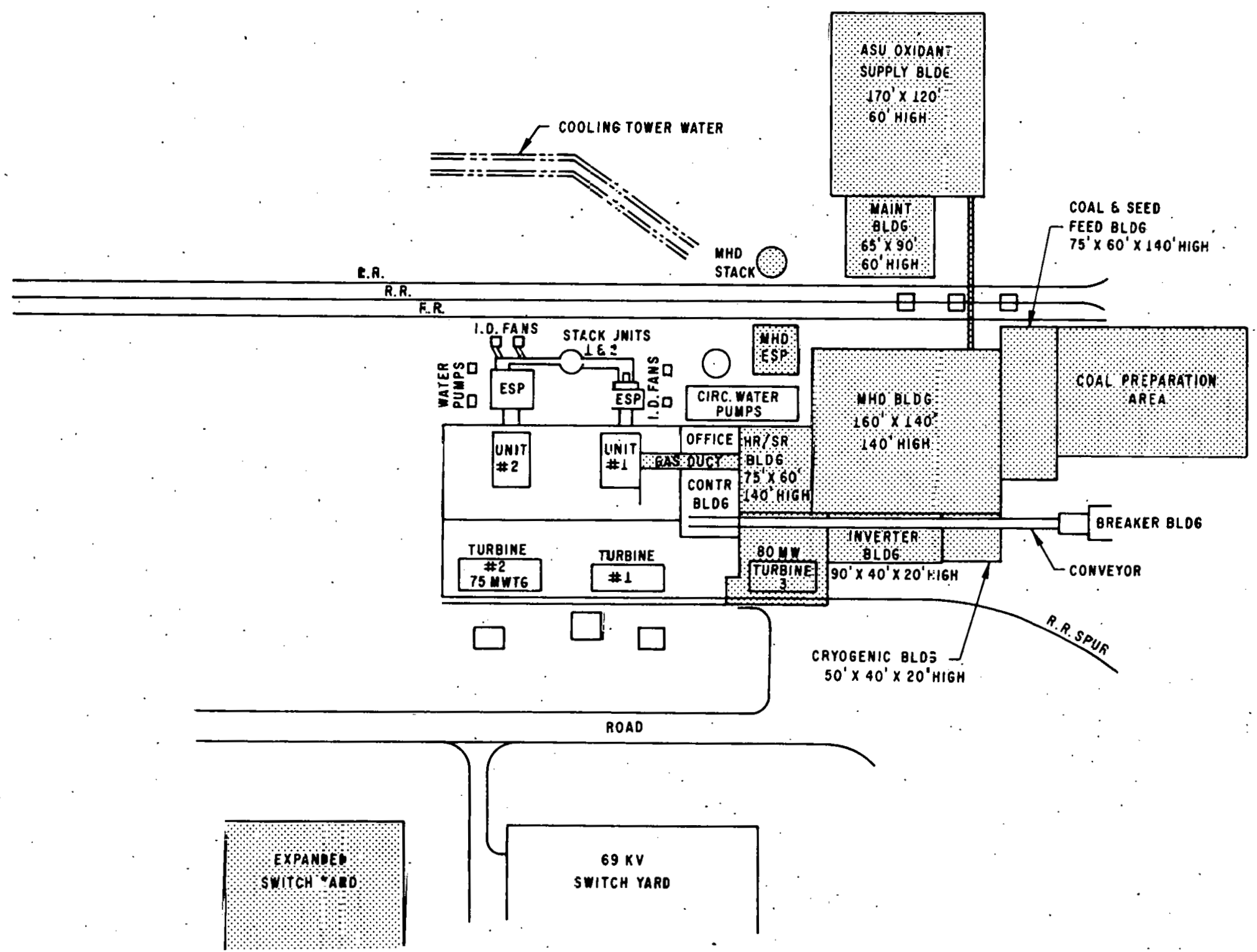

Figure 8: Vermilion Retrofit -- Areas of New Buildings 
water treatment plant or the coal conveyor. For illustration, the MHD buildings are shown adjacent to Boiler \#2). These structures include buildings for coal and seed feed, control, cryogenic for the magnet, electrical inverters and switchgear, channel maintenance, MHD power train, HRSR train, and oxygen supply. 


\section{THIS PAGE}

\section{WAS INTENTIONALLY LEFT BLANK}




\section{PLANT FEATURES FAVORABLE FOR RETROFIT}

Although the Vermilion site appears practical for an MHD retrofit, it is not ideal, primarily because of the lack of space adjacent to Boiler \#1. Characteristics of a more desirable site for retrofitting include the following features:

-1. Sufficient open space adjacent to the boiler for the MHD buildings.

2. Access to the existing boiler for the duct carrying the MHD gases.

3. Space to enlarge the ESP or add a baghouse to the conventional plant, in order to handle the increased solids loading of the gases.

4. Conventional plant size in the range of 150 to $300-M W$ (electrical). If it is smaller, there is a greater likelihood that access to the boiler will be more difficult, as exemplified by the Vermilion boiler. The present state of the technology for building large MHD components seems to impose an upper limit on the size of a near-term retrofit.

5. Sufficient cooling water available for an increase in plant capacity.

6. Because MHD has the potential for low emissions from even high-sulfur coals, retrofit would be especially attractive for a plant with unresolved environmental problems, or one near a supply uf high-sulfur coal.

7. A wet-bottom boiler would be an advantage, because much of the equipment necessary to handle discharged seed would already be in place. Also, the boiler should be equipped with wall soot blowers, which would be used to dislodge solid seed deposits from the water-cooled walls.

8. A boiler designed for lower combustion gas temperature.

9. Adequate electrical transmission lines. 
THIS PAGE

\section{WAS INTENTIONALLY LEFT BLANK}




\section{COST EFFECTIVENESS OF MHD RETROFIT}

Two life-cycle costs studies $[31,32]$ were made to estimate the financial benefits to a utility of adding an MHD topping cycle to an old unit as compared to other options, such as building a new conventional plant on a new site, or modifying the existing plant to meet New Source Performance Standards (NSPS). for $\mathrm{SO}_{2}$ emissions. The studies indicate a financial advantage of an MHD retrofit over adding a limestone scrubber to the present plant, or burning higher cost, low sulfur coal to meet $\mathrm{SO}_{2}$ emission standards. This advantage improves as the plant utilization and size increase. The $240 \mathrm{MW}$ (electrical) MHD retrofit also appears to be advantageous compared to a new plant on a new site, even though the costs of licensing a new site are ignored. The advantage of the MHD plant can be attributed to its lower fuel costs and its capability to remove $\mathrm{SO}_{2}$ from the flue gas at an overall cost that is comparable to a 1 imestone scrubber.

\section{A. Cost of MHD Retrofit vs. New Conventional Plant}

The first study [31] was a comparison of the life-cycle cost of the MHD retrofit of the Vermilion unit with the cost of a new; conventional coal-fired unit, erected on a new site. Each plant will have a $240 \mathrm{MW}($ electrical) output and a, 30 year plant life. The MHD plant was calculated to have a heat rate of $8800 \mathrm{BTU} / \mathrm{kWhr}$ and the conventional plant to have a heat rate of 10,700 BTU/kWhr. Both units would burn Illinois \#6 coal with a HHV of 10,500 BTU/1b and will meet the NSPS for $\mathrm{SO}_{2}$ emissions. The MHD retrofit would use the potassium seed material to remove $\mathrm{SO}_{2}$ in conjunction with an off-site reprocessing plant to separate sulfur from the spent seed and return a low sulfur potassium product. The conventional plant will have a limestone scrubber for flue gas desulfurization.

The total equivalent capital investment (ECI) in 1981 dollars was used for this comparison. The ECI of operating and maintenance (O\&M) costs is a method of obtaining equivalent capital costs from costs that will occur periodically in the future. In this manner, the 0\&M costs can be added directly to estimated capital investment costs to obtain a total ECI. The ECI method enables a comparison of various alternatives based on a single figure of economic merit. This method is analogous to the present worth of total 
revenue required, which is the technique used by EPRI [33] to evaluate alternative investments.

Table 10 is a comparison of the estimated ECI costs for the two cases. The economic parameters that were used are listed in Table 11, and a breakdown by major accounts of the direct construction cost of the conventional unit is given in Table 17. Site development costs are included. The direct construction cost of the MHD retrofit unit, summarized in Table 13, was based on cost estimates developed by Gilbert and Associates, and Avco Everett Research Laboratory [34] for a new, complete, combined-cycle coal-fired MHD plant of a Eize similar to the Vermilion retrofit. These cusls, were developen for $a$ first-of-a kind plant and reflect conservative designs for the conventional and MHID components. The result is that the combined cysle plant costs are approximately $\$ 350 / \mathrm{kW}$ more than the direct construction costs of a conventional coal-fired plant with a FGD scrubber. Later model plants should be less costly than the initial plant. Direct retrofit construction cost also includes the cost of existing plant modifications necessary to accommodate the MHD topping plant, but it excludes the cost of any necessary refurbishments of the existing plant.

The costs obtained are at a January 1981 price level and exclude escalation during construction, taxes, and Allowance for Funds used During Construction $(A F D C)$. The AFDC would affect the results if the construction schedule of one case was significantly different than the construction schedule of the other. Included in the total ECI costs of the two cases are direct construction costs, indirect costs (design and engineering, utility overhead, and construction management costs), and major operating and maintenance (0\&M) costs.

The FGD system included in the standard, coal-fired case is based on conventional lime stone scrubbers with waste stabilization and offsite disposal. FGD waste disposal 0\&M costs included the costs for the associated labor, and for equipment replacement such as trucks and bulldozers. The seed reprocessing costs are calculated as ECI as if an offsite chemical processing company were responsible for separating sulfur from the recovered, spent seed material and returning regenerated seed plus any make-up material to the power plant. This cost was derived from an evaluation [35] of several candidate 
TABLE 10: Life-Cycle Cost Comparison of New Coal-fired Unit and MHD Retrofit

\section{$240 \mathrm{MW}(\mathrm{electrical)}$ Conventional Coal- Fired Unit}

$240 \mathrm{MW}$

(electrical)

MHD Retrofit Unit
A. Direct Construction Cost

B. Indirect Costs During Constr.

C. Operating Costs (as ECI)

1. fuel

2. lime

3. FGD waste disposal 0\&M costs

4. seed reprocessing 0\&M costs

5. channel refurbishment

Total. Operating Costs

D. Total Equivalent Capital

Investment (1981 dollars)

E. Differential Equivalent Capital

Inves tment
$\$ 272,000,000^{\mathrm{a}}$

$42,000,000$.

$\$ 344,000,000$

$\$ 36,000,000$

$\$ 10,000,000$

--.--

$----$

$\$ 390,000,000$

$\$ 704,000,000$

$\$ 50,000,000$
$\$ 2.65,000,000^{b}$

$\$ 41,000,000$.

$\$ 283,000,000$



$\$ 43,000,000$

$\$ 22,000,000$

$\$ 348,000,000$

$\$ 654,000,000$

Base

NOTES: Costs are ECI reduced to January 1981. Escalation during construction, taxes, and Allowance for Funds used During Construction (AFDC) are excluded. No differential costs have been included for possible permitting differences:

a Breakdown of this cost is included in Table (12).

b Includes existing plant modifications costs; excludes refurbishmenl costs. 
TABLE 11: Assumed Economic Parameters

A: Economic Parameters and Design Basis Developed by Sargent and Lundy

$\ldots \ldots-\ldots-\ldots-\ldots-\ldots-\ldots-\ldots-$

Present Value Rate (Discount Rate)

$12.9 \% / \mathrm{yr}$

Escalation Rate:

Labor

Coal

Chemical

$7.5 \% / \mathrm{yr}$

$10.5 \% / y r$

$10.5 \% / \mathrm{yr}$

Levelized Fixed Charge Rate

$18.5 \% / y r$

Coal Cost (1981 dollars)

$1.35 \$ /$ MDtus

Current Delivered Chemical Cost:

l ime

$70 \$ /$ ton

NOTE: Typical present day values for a central Illinois utility.

B: Costs and Parameters Supplied by Argonne

$-\cdots-\cdots-\cdots$

Total Direct Construction Cost-MHD Retrofit. $\$ 265,000,000$

Cost of Seed Reprocessing

$\$ 3,000,000 / \mathrm{yr}$

Cost of Channel Refurbishment

$\$ 2,000,000 / \mathrm{yr}$

No. of Channel Refurbishments

$3 / \mathrm{yr}$

Capacity Factor

$70 \%$

NOTE: Above present day values: 
TABLE 12: Dịrect Construction Costs for a New Coai-fired Unit

FERC

Account

310

311

312

314

315

316

352

353

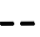

Description

Land and Land Rights

Structures and Improvements

Boiler Plant

Turbine. Plant

Accessory Electrical Equipment

Miscellaneous Power Plant Equipment

Substation Structures

Substation Equipment

FGD Waste Disposal Equipment

Total Estimated Construction Costs (based on a 40 hour week)
Direct Cost

$(\$ 1000)$

300

64,349

143,944

39,973

16,442

4,517

32

982

1,781

272,320 
TABLE 13: Estimated Retrofit cost

1. MHD Topping Train

(Includes channel, nozzle and diffuser, combustor included in Item 7)

2. Superconducting Magnet

3. Retrofit Steam Plant - HRSR

4/5. Baghouse, ID Fan, Stack

6. Oxygen plant.

$\left(2\right.$ units each 1100 IPU $\mathrm{U}_{2}$ at $42 \% \quad \mathrm{O}_{2}$,
includes air and oxidant compressors)

7. Primary Combustor, Coal and Seed Feed

Systems

8. Turbines and Generator

(Compressors in Item 6)

9. Cooling towers

10. Slag-Spent Seed Handling

11. Inverters and Load Conditioners

12. Buildings, Site Improvements, and Uther Conventional Equipment

13. Modifications to Existing Plant 
seed reprocessing techniques: It was assumed that the seed regeneration facility would use a process similar to the Tampella process, [36] which is employed by the Kraft paper industry to regenerate the spent $\mathrm{NaSO}_{4}$ pulping salts.

Channel refurbishment costs allow for rebuilding a channel three times per year, and include removing the used channel from the power train and replacing it with the rebuilt channel three times per year during scheduled plant outages. The costs are based on Argonne's experience in the building and assembly of an MHD channel of a size comparable to the Vermilion retrofit channel.

In order to compare life cycle costs of a new plant with the costs of retrofitting an old plant, such as Vermilion, the refurbishing costs must be included. These costs, which are highly site specific, were not obtained for the Vermilion plant. Examples of equipment that might require total replacement instead of regular maintenance include the boiler superheater, reheater, lower wall, and floor tubes, flue gas ductwork, ID fans, electrostatic precipitator, steel chimney lining, main and auxiliary condenser tubes, and crusher building coal handling fire protection system. The refurbishment costs must include demolition and disposal of the replaced equipment. Also neglected because they are site specific, are the costs of obtaining licenses and permits for the new site and for the increased capacity at the existing site.

The direct cost of the retrofit (see Table.10) is relatively close to that of the new conventional coal-fired unit. The ECI cost of the limestone scrubber for FGD is similar to the costs associated with the seed material, which is used to remove sulfur in the MHD system. The greatest cost saving of the retrofit is the fuel costs, because the MHD unit has a higher plant efficiency. The ECI of the fuel cost over the 30 year plant life is approximately $\$ 61,000,000$ less for the MHD retrofit which results in an estimated ECI cost advantage of $\$ 50,000,000$ for the MHD retrofit before the refurbishing costs. The fuel cost assumed for this study, $\$ 1.35 / \mathrm{MBtu}(\$ 30 /$ ton), is significantly lower that the average cost of Illinois coal (\$37.50/ton) being purchased currently by Commonwealth Edison [37]. The potential benefit from 
retrofitting with MHD appears very attractive; the actual benefit would depend on refurbishing costs that are site specific and on prevailing coal costs.

\section{B. Cost of MHD Retrofit vs. Scrubber Retrofit}

The second life cycle cost analyses [32], using different economic factors and, more current fuel costs, compared the rates of return on investments for three retrofit options using the present Vermilion Boiler \#1 as a basis. These options are listed in Table 14.

It was assumed for Alternative 0 that the present Vermilion \#1 unit would be refurbished and operated for a 30 year period, but in order tio iitil. $s n_{2}$ emission restrictions low-sulfur western coal (at $\$ 46.50$ per ton) would be burned. The other alternatives would be capable of burning less costly, high sulfur lllinois coal ( $\$ 37.50$ per ton) because the $\mathrm{SO}_{2}$ would be removed by the limestone scrubber or the MHD seed material. However, these alternatives would involve an investment in addition to the cost of refurbishing the existing $75 \mathrm{MW}$ unit. The purpose of this cost analysis was to determine the rate of return on these additional investments under two operating scenarios. In Scenario A, all plants would be operated at a $65 \%$ capacity factor; in Scenario $B$, the smaller plants would be operated at a capacity factor of $40 \%$ typiral nf a peaking unit and the two larger MHD plants at a base-load capacity factor of $70 \%$.

The estimated capital cost of the scrubber option was derived from a Commonwealth Edison study [28,37] of the conversion of a $1100 \mathrm{MW}$ (electrical) oil-fired plant to coal burning. The capital costs of the MHD options were developed by Argonne from a conceptual design study of a first generation combined cycle MHD plant [34]. Fixed and variable O\&M costs for all alternatives were based on the Commonwealth Edison study.

Fixed 0\&M costs for Alternative 0 were based on $50 \%$ of the fixed costs of the $1100 \mathrm{MW}$ plant without scrubbers, and for Alternatives 1,2 and 3 they were based on a similar factor of the fixed costs of the $1100 \mathrm{MW}$ plant with scrubbers. All variable 0\&M costs were assumed to be directly related to the size of the plant or the annual fuel consumption. For the MHD options, the 
extra costs associated with rebuilding the channel and reprocessing the MHD seed material were estimated as described in the first cost comparison study. A summary of operating and maintenance costs is given in Table. 15.

For each scenario, the cost of producing power in the existing plant (Alternative 0) for the Base Year (1981) was calculated as,

$$
\underset{(\$ / k W h r)}{(\text { Revenue Rate })}=\frac{(\text { Total 0\&M Costs })+(\text { Fuel Costs })}{\text { Annual Power Output }(\mathrm{kWhr})}
$$

and this cost was assumed to be the revenue rate for the three retrofit alternatives. Because the costs for the existing plant varied as a result of the different utilization rate assumptions, the revenue rates for the two scenarios were different. The total annual revenue for an option was calculated by

\section{(Annual Power Output) $\times$ (Revenue Rate) $\times$ (Escalation).}

( $k$ Whr/yr)

$(\$ / \mathrm{kWhr})$

Thus, this methodology yielded a incremental revenue rate for each retrofit option that could be compared to the additional investment required for that option. A summary of the calculations leading up to the costs and revenue for each alternative for the first year of operation (1981) is presented in Table 16. The escalation factors for costs and revenue, and other financial assumptions are listed in Table 17.

The results of the financial analyses are given in Table 18 . From these results; it is clear that the scrubber retrofit is disadvantageous compared to continuing operations in the present unit despite the differences in fuel costs. The capability of the scrubber retrofit to burn lower cost coal is more than offset by the lower efficiency and the higher scrubber operating costs. On the other hand, the MHD units provide the same sulfur removal capabilities as the scrubber, but have a.significantly higher efficiency. Despite the high operating costs attributable to the MHD components, the higher efficiency and lower cost fuel lead to a cost benefit for the MHD retrofits especially for the larger unit. 
TABLE 14: Alternatives for Second Life-Cycle Cost Study

Alternative

Estimated

Addi tional

Investment

$\frac{\text { Capacity Factors }}{\text { Scenario }}$

A

B

\begin{tabular}{ccccc}
\hline $0-$ Existing 75 MW unit & 0 (Base) & $65 \%$ & $40 \%$ \\
$1-75$ Mw with scrubber & $\$ 28,000,000$ & $65 \%$ & $40 \%$ \\
$2-125$ Mw MHD Retrofit & $\$ 205,000,000$ & $65 \%$ & $70 \%$ \\
$3-240$ Mw MHD Retrnfit & $\$ 310,000,000$ & $65 \%$ & $70 \%$
\end{tabular}

TABLE 15: Summary of Operations and Maintenance Costs for Base Year (1981)

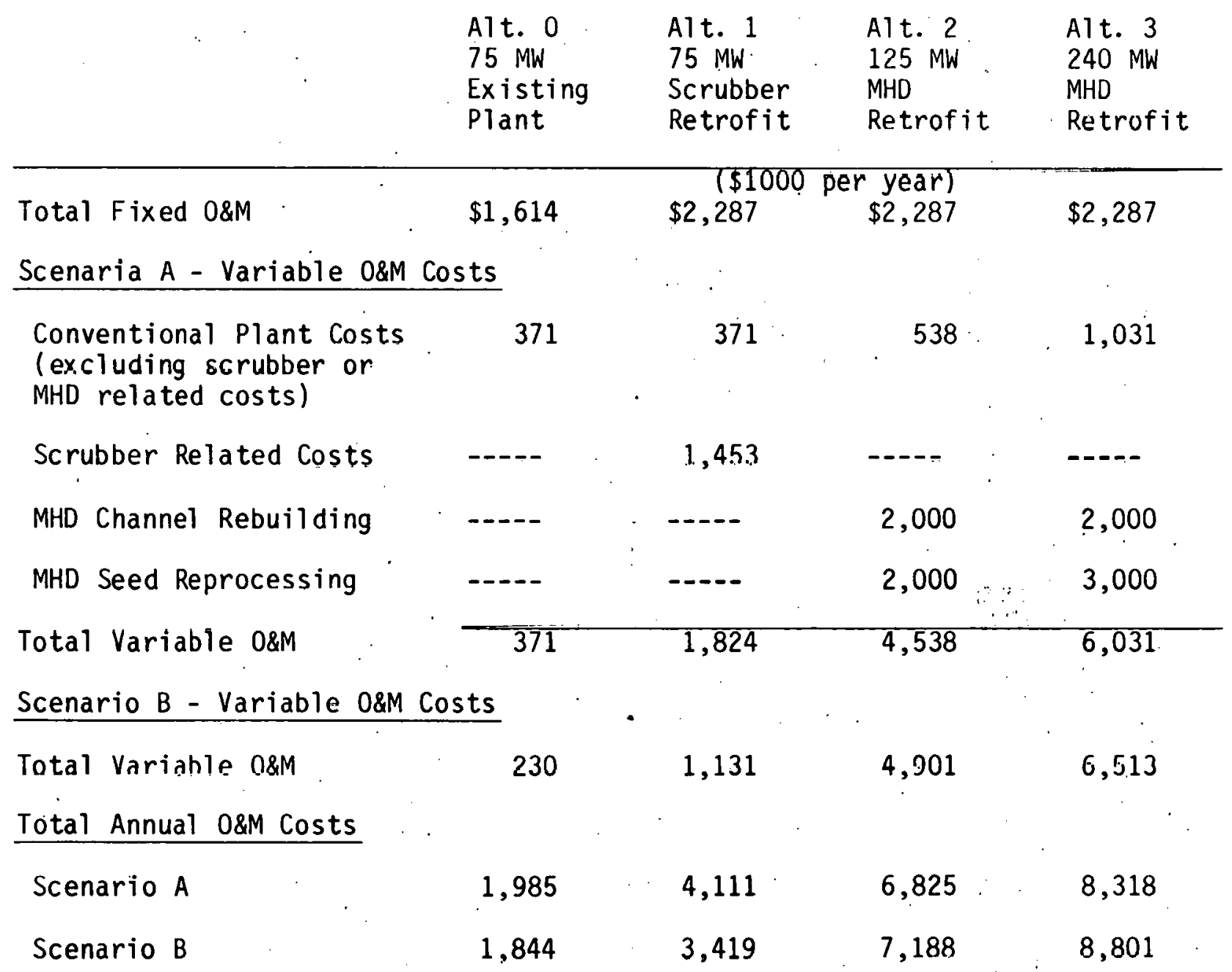


TABLE 16: Summary of Data by Alternative for Base Year (1981)

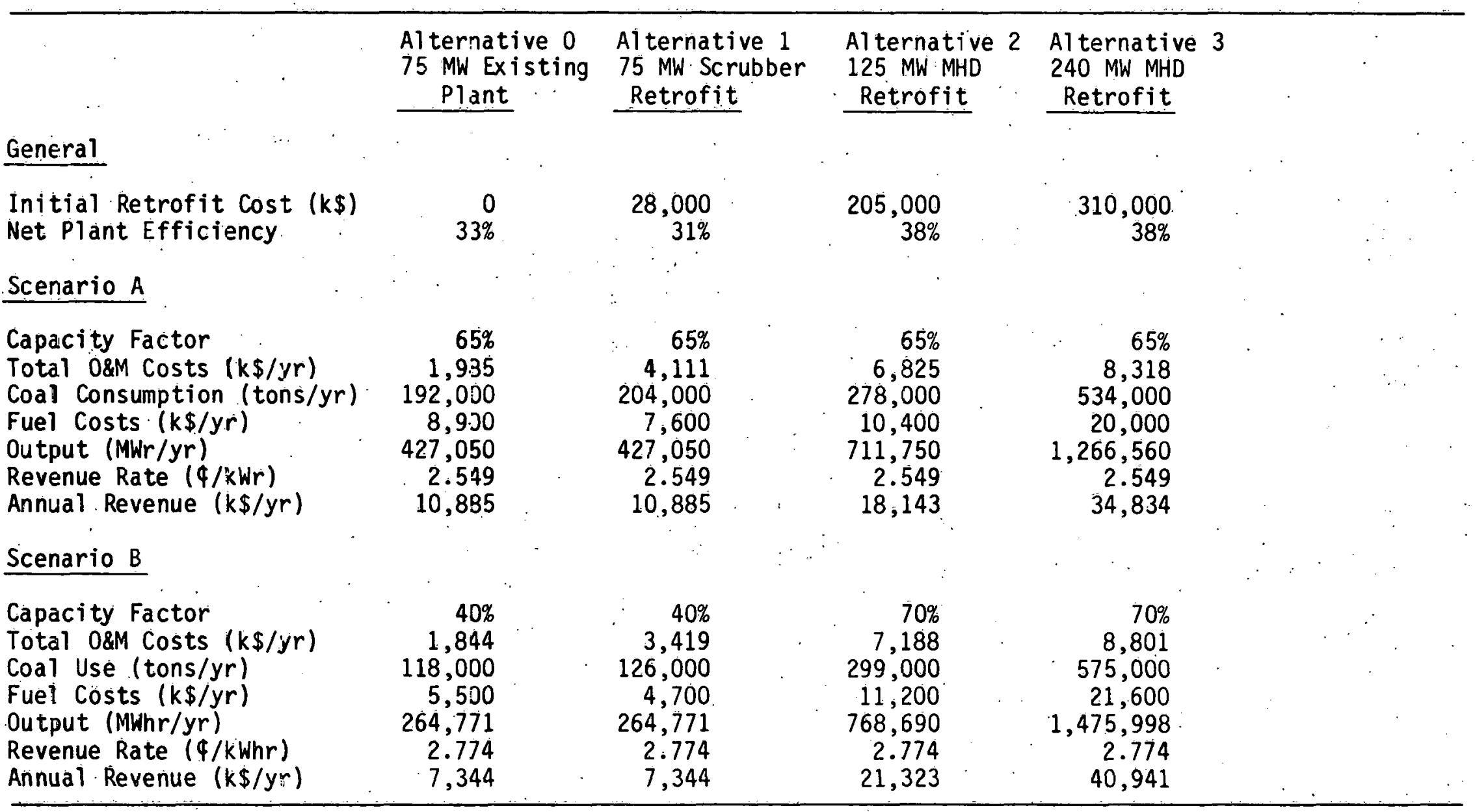




\begin{tabular}{lcl} 
Description & $\frac{\text { Value }}{30 \text { years }}$ & $\frac{\text { Source }}{\text { ANL }}$ \\
Salvage Value & $\$ 0$ & ANL \\
Tax Rate & $48 \%$ & CWE Study [37] \\
Minimum Yield (Discount Rate) & $11 \%$ & CWE Study [37], \\
$\begin{array}{l}\text { Annual Operations and } \\
\text { Maintenance Cost } \\
\text { Escalation }\end{array}$ & $8 \%$ & CWE Study [37] \\
Annual Coal Cost Escalation & $11 \%$ & Energy User News \\
Anlludl Revenue Escalation & $15 \%$ & Energy User News \\
\hline
\end{tabular}

TABLE 18: Summary of Comparative Financial Results (After Taxes)

\begin{tabular}{|c|c|c|c|c|}
\hline$\cdot$ & . & $\begin{array}{l}\text { A1 lernative } 1 \\
75 \text { MW Scrubler } \\
\text { Retrofit } \\
\end{array}$ & $\begin{array}{c}\text { Alternative } 2 \\
125 \mathrm{MW} \mathrm{MHÜ} \\
\text { Retrofit }\end{array}$ & $\begin{array}{l}\text { Alternative } 3 \\
240 \mathrm{MW} M H D \\
\text { Retrofit }\end{array}$ \\
\hline Uriginal Investment & & $\$ 28,000,000$ & $\$ 205,000,000$ & $\$ 310,000,000$ \\
\hline $\begin{array}{l}\text { Scenario A } \\
\text { Assumed Revenue Rato } \\
\text { Capacity Factor } \\
\text { Payback } \\
\text { Net Present Value } \\
\text { Internal Rate of Return }\end{array}$ & & $\begin{array}{l}2.554 / \mathrm{kWhr} \\
\quad 65 \% \\
31.3 \text { years } \\
(\$ 26,500,0 n n)^{\star \star} \\
(0.78 \%)\end{array}$ & $\begin{array}{l}2.554 / \mathrm{kWhr} \\
65 \% \\
17.8 \text { years } \\
\$ 66,000,000 \\
8.73 \%\end{array}$ & $\begin{array}{l}2.55 \$ / k \text { Whr } \\
\quad 65 \% \\
13.8 \text { years } \\
\$ 104,700,000 \\
12.78 \%\end{array}$ \\
\hline $\begin{array}{l}\text { Scenario B } \\
\text { Assumed Revenue Rate } \\
\text { Capacity Factor } \\
\text { Payback } \\
\text { Net Present Value } \\
\text { Internal Rate of Return }\end{array}$ & . & $\begin{array}{l}2.77 \$ / \mathrm{kWhr} \\
40 \% \\
\star \\
\underset{\star}{\$ 161,800)^{\star \star}} \\
{ }^{\star}\end{array}$ & $\begin{array}{l}2.774 / \mathrm{kWhr} \\
70 \% \\
14.63 \text { years } \\
\$ 35,400,000 \\
11.95 \%\end{array}$ & $\begin{array}{l}2.774 / \mathrm{kWhr} \\
70 \% \\
12.04 \text { years } \\
\$ 265,800,000 \\
14.94 \%\end{array}$ \\
\hline
\end{tabular}

* Negative total cash flow makes this value meaningless

$\star \star$ Negative values 


\section{Extrapolation of Potential Benefit of MHD Retrofit to Larger Size Plants}

A slightly different approach [38,39] was pursued by Argonne for the purpose of extrapolating economic predictions for the retrofit of rarger capacity power plants. In this effort, the economic results for the MHD Retrofit as indicated in Table $10(\mathrm{col} .2)$ were used as a starting point. In this analysis the MHD retrofit was compared against the combination of an existing plant retrofitted with a FGD scrubber and purchasing the requisite incremental power from a grid supplied by a new 1100 . MW(electricall) coal-fired plant with scrubbers. To simulate this concept, a constant specific costs for the purchase of energy from power grid was used in the extrapolation model.

Table 19 compares the two alternatives for obtaining 170 MW(electrical) of additional power. The first column lists information for the MHD retrofit alternative, which is equivalent to the retrofit of Vermilion. Boiler \#1 as described in this report. Columns 2 and 3 provide information for the combination of the existing plant retrofited with $F G D$ scrubbers and a second power source to supply the incremental capacity from the power grid. The equivalent total capacity for the two alternatives is listed in Row 1 . In Row 2 , the capacity factors for the new MHD plant and existing plants are shown. Based on these capacity factors and the capacity Row 1, the electrcity (Row 3) is computed from Columns 1 and $2\left(E=C \times C_{f} \times 8760\right)$. The electricity needed from the grid (Row 3, Col. 3 ) is simply Col. 1 - Coll. 2.

Initial investment (Row 4). includes the cost of modifications to the existing plant for the MHD retrofit alternative and cost of the FGD scrubber retrofit to the existing plant for the conventional alternative. The capital cost for grid power used is based upon the specific capital costs (Row 5, Col. 3) of $1250 \$ / \mathrm{kW}$ [40]. The specific capital costs for the retrofit increment (Row 5, Col. 1) is $1825 \$ / \mathrm{kW}(\$ 310,000,000 / 170,000 \mathrm{~kW})$, while the power grid investment is $\$ 212,000,000(1250 \$ / \mathrm{kW} \times 70,000 \mathrm{~kW})$.

Operating costs (Row 6) consists of the fuel and 0\&M costs over the plant lifetime, and also FGD scrubber maintenance costs associated with lime and waste disposal for the conventional alternative, and seed reprocessing and 
TABLE 19: Cost Comparison 70/240 MW(electrical) Power System

Description of alternative

Basic 240 MW(electrical) MHD retrofit power plant

al ternative

MHD retrofit New power plant alternative

Allternative Existing Power from

Power Plant System Grid

1. Capacity, $10^{3} \mathrm{~kW} \quad 240 / 170 \quad 70 \quad 170$

2. Capacity factor

$0.70 \quad 0.45$

3. Electricity, $10^{9} \mathrm{kWhr}$

1.47

0.28

1.19

4. Injtial investment, $10^{6} \$$

306

38

212

5. Specific initial investment for incremental

capacity, $\$ / \mathrm{kW}$

1800

$-\cdots$

1250

6. Operational \& maintenance cost (as equivalent in (tial investment), $10^{6} \$$

348

90

345

7. Specific operation of maintenance cost, $\$ / k W h r$

0.237

0.322

0.290

8. Subtotal equivalent capital inyes tment $(4+6)$; $10^{6} \$$

654 128

557

9. Total equivalept capital investment, $10^{6} \$$ 654

685

10. Gain in total equivalent capital investment if MHD retrofit alternative is used, $10^{6} \$$

11. Relative gain in total equivalent capital investment if MHD retrofit is used $(10 \div 9) \times 100, \%$ 
channel maintenance for the MHD retrofit alternative. The 0\&M costs for additional grid capacity (Row 6$)$ is based on specific 0\&M costs $(0.290 \$ / \mathrm{kWh}$ ) $[41,42,43]$ and is calculated by multiplying the electricity (Row 3) by the specific 0\&M costs (Row 7). The specific 0\&M costs for Columns 1 and 2 are based on 0\&M costs (Row 6) and electricity (Row 3).

Row 8 shows the ECI for the two power system alternatives: MHD retrofit vs an existing plant with FGD scrubbers and additional power capacity. Row 9 lists the total ECI for two alternatives, and Row 10 the relative gain if the MHD option is chosen. Note that, for a plant the size of the Vermilion \#l, this will result in an equivalent gain of $\$ 31,000,000$, based on the retrofit design and the assumptions made.

The same calculation was performed for larger power systems with both power and cost results scaled from the Vermilion scenario. Table 20 shows a $90 \mathrm{MW}(e l e c t r i c a l)$ plant retrofited with MHD to a total capacity of $300 \mathrm{MW}$. Table 21 has a 150/500 MW(electrical) power system; Table 22, 210/700 MW (electrical); Table 23, 270/900 MW(electrical), and Table 24, 330/1100 MW (electrical). In Tables 20-24 the two specific costs for energy from the. power grid (1250 $\$ / \mathrm{kW}$ and $0.290 \$ / \mathrm{kWhr}$ ) are constant while the specific costs for the retrofit and FGD alternatives vary according to the methodology described below.

Two estimates of MHD retrofit cost scaling criteria are given, so as to reflect a range of scaling of the rather uncertain MHD component cost data now available. This range in projected investment required for MHD retrofit of progressively larger existing power plants is reflected in Figure 9 . Two curves are used to project the diminishing specific cost of retrofitting the existing plant. Contemporary MHD research indicates an improved benefit of scale compared to conventional plant data. Similarly, a summary of the change in efficiency that can be expected from retrofitting existing power plants of increasing capacity with MHD is shown in Figure 10. Again, the efficiency gain for increasing size is much better for MHD plants than for conventional. plants. These curves were used to extrapolate the cost of power for plants larger than the $70 \mathrm{MW}($ electrical) plant. 


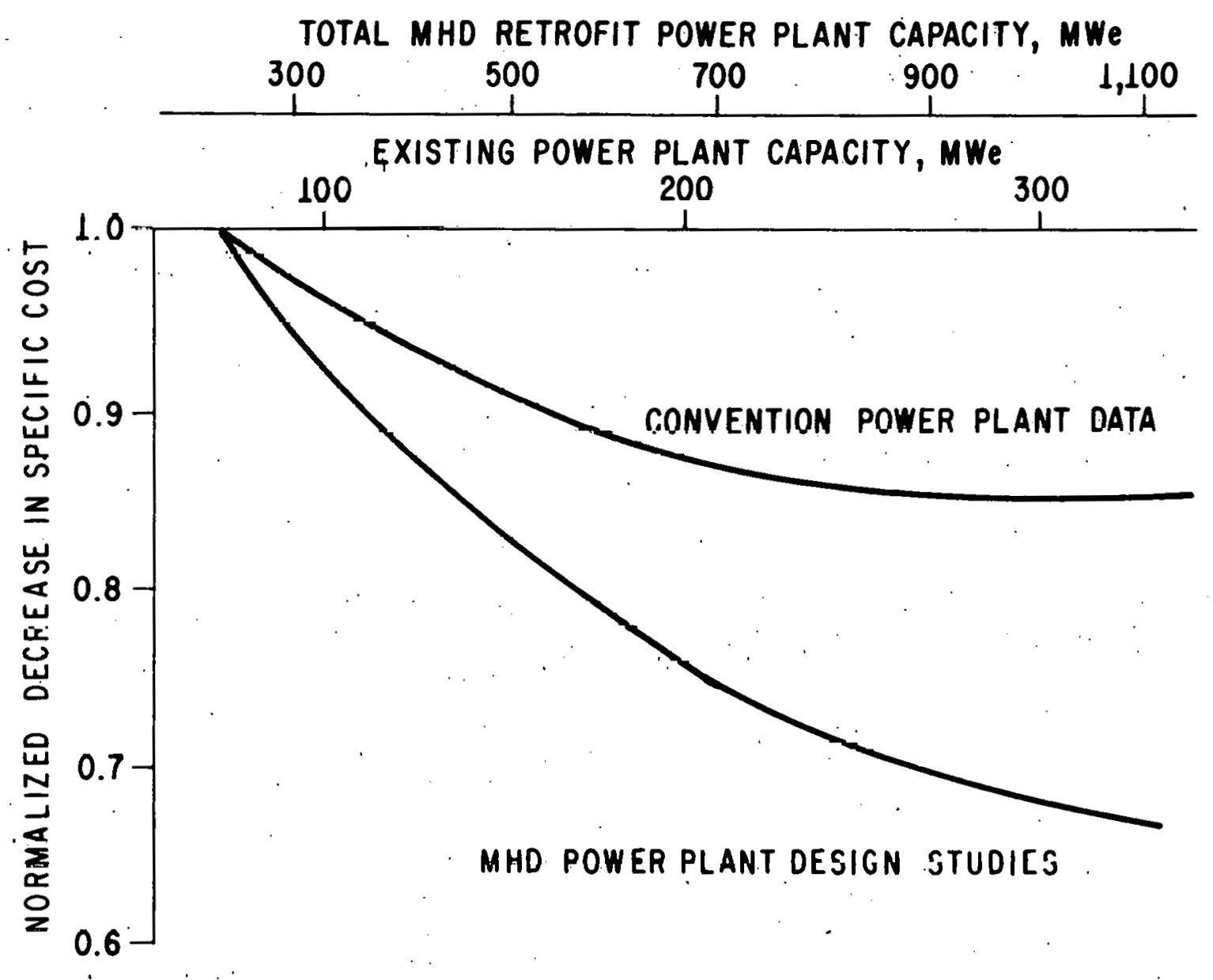

Figure 9: Relative Change in the Cost of MHD Retrofits of Increasing Capacity 


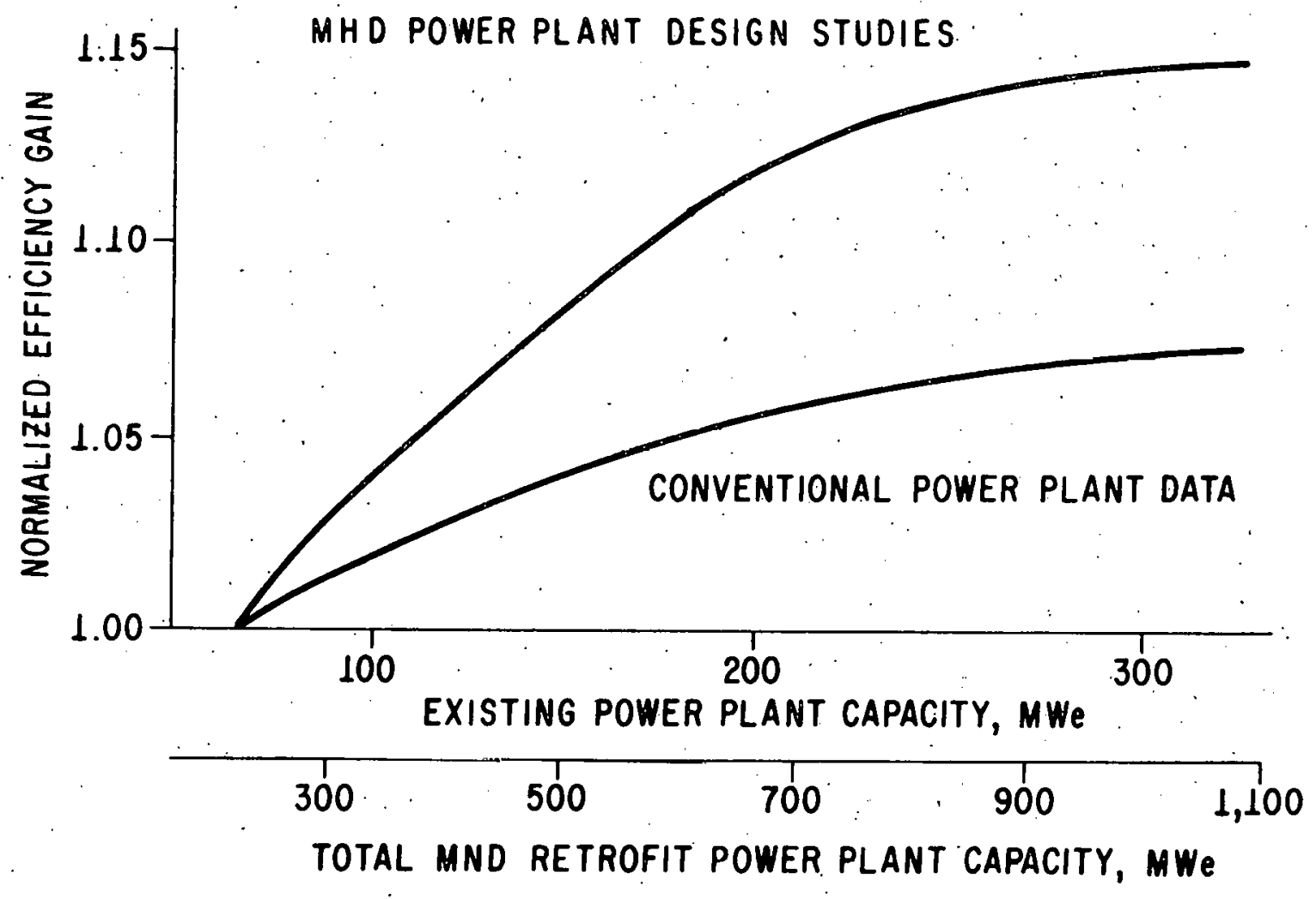

Figure 10: Relative Change in Plant Efficiency for MHO Retrofits of Increasing Capacity 
TABLE 20: Cost Comparison 90/300 MW(electrical) Power System Description of al ternative

Evaluated MHD retrofit power plant alternative of $300 \mathrm{Mw}($ electrical)

MHD retrofit New power plant alternative

Allternative Existing Power from Power Plant System Grid

1. Capacity, $10^{3} \mathrm{~kW} \quad 300 \quad 90 \quad 210$

2. Capacity factor $\quad 0.70 \quad 0.45 \quad-$

3. Electricity, $10^{9} \mathrm{kWhr} \quad 1.84 \quad 0.35 \quad 1.19$

4. Initial investment, $10^{6} \$$

$350 / 362$

35

262

5. Specific initial investment for incremental

capacity, $\$ / \mathrm{kW}$

$1667 / 1725$

1250

6. Operational \& maintenance cost (as equivalent initial investment), $10^{6} \$$

$419 / 426$

112

432

7. Specific operation of ma intenance cost, $\$ / \mathrm{kWh} r$.

$0.228 / 0.232$

0.32

0.290

8. Sub total equivalent capital investment $(4+6), 10^{6}$ $769 / 788$ 152 694

9. Total equivalept capital inves tment, $10 \$$

10: Ga in in total equivalent capital investment if MHU retrofit alternative is used. $10^{6} \$$

$78 / 59$

11. Relative gain in total equivalenl capital investiment if MHD retrofit is used $(10 \div 9) \times 100, \%$

$9.2 / 7.0$ 
TABLE 21: Cost Comparison 150/500 MW(electrical) Power System Description of al ternative

Evaluated MHD retrofit power plant alternative of $500 \mathrm{Mw}($ electrical)

MHD retrofit New power plant alternative

Allternative Existing Power from

Power Plant System Grid

1. Capacity, $10^{3} \mathrm{~kW} \quad 500 \quad 150 \quad 350$

2. Capacity factor $0.70-0.50 \quad-$

3. Electricity, $10^{9} \mathrm{kWhr} \quad 3.06 \quad 0.66 \quad 2.40$

\begin{tabular}{llllll}
\hline 4. Injtial investment, & $497 / 560$ & 45 & & 437 \\
$10^{6} \$$ & & 497
\end{tabular}

5. Specific initial investment for incremental

capacity, \$/kW $1420 / 1600 \quad----\quad 1250$

6. Operational \& maintenance cost (as equivalent initial investment), $10^{6} \$ 658 / 693 \quad 208 \quad 696$

7. Specific operation of $\begin{array}{llll}\text { maintenance cost, } \$ / \mathrm{kWhr} & 0.215 / 0.227 & 0.315 & 0.290\end{array}$

8. Subtotal equivalent capital inyes tment $(4+6)$, $10^{6} \$$

$1155 / 1253 \quad 253$

1133

9. Total equivalept capital investment, $10^{6} \quad \therefore \quad 1155 / 1253 \quad 1386$

10. Gain in total equivalent capital investment if MHD retrofit alternative is used, $10^{6} \$$ $231 / 133$

11. Relative gain in total equivalent capital investment if MHD retrofit is used $(10 \div 9) \times 100, \%$ $16.7 / 9.6$ 
TABLE 22: Cost Comparison 210/700 MW(electrical) Power System Description of al ternative

Evaluate MHD retrofit power plant al ternative of $700 \mathrm{Mw}$ (electrical) MHD retrofit New power plant alternative Allternative Existing Power from Power Plant System Grid

1. Capacity, $10^{3} \mathrm{~kW} \quad 700 \quad 210 \quad 490$

2. Capacity factor $0.70 \quad 0.55$

3. Electricity, $10^{9} \mathrm{kWhr} \quad 4.29 \quad 3.01$

\begin{tabular}{|c|c|c|c|c|}
\hline & $\begin{array}{l}\text { Initial investment, } \\
10^{6} \$\end{array}$ & $638 / 759$ & 50 & 612 \\
\hline 5. & $\begin{array}{l}\text { Specific initial invest- } \\
\text { ment for incremental } \\
\text { capacity, } \$ / \mathrm{kW}\end{array}$ & $1300 / 1550$ & --- & 1250 \\
\hline 6. & $\begin{array}{l}\text { Operational \& maintenance } \\
\text { cost (as equivalent } \\
\text { initial investment) } \\
10^{6} \$\end{array}$ & $896 / 954$ & 313 & 951 \\
\hline 7. & $\begin{array}{l}\text { Specific operation of } \\
\text { maintenance cost, } \$ / \mathrm{kWhr}\end{array}$ & $0.209 / 0.222$ & 0.310 & 0.290 \\
\hline 8 . & $\begin{array}{l}\text { Subtotal equivalent capital } \\
\text { inyes linent }(4+6) \text {, } \\
10^{6} \$\end{array}$ & $1534 / 1713$ & 363 & 1563 \\
\hline 9 . & $\begin{array}{l}\text { Total equivalept capital } \\
\text { investment, } 10^{6} \$\end{array}$ & $1534 / 1713$ & 1926 & \\
\hline & $\begin{array}{l}\text { Gain in total equivalent cap } \\
\text { investment if MHD retrofit } \\
\text { native is used, } 10^{6} \$\end{array}$ & ital & $392 / 213$ & \\
\hline 11 . & $\begin{array}{l}\text { Relative gain in total equil } \\
\text { capital investment if MHD re } \\
\text { is used }(10 \div 9) \times 100, \%\end{array}$ & $\begin{array}{l}\text { lent } \\
\text { rofit }\end{array}$ & $20.3 / 11.1$ & \\
\hline
\end{tabular}


TABLE 23: Cost Comparison 270/900 MW(electrical) Power System Description of al ternative

Evaluated MHD retrofit power plant aiternative of $900 \mathrm{Mw}($ electrical)

MHD retrofit New power plánt alternative

Allternative Existing Power from

Power Plant System Grid

1. Capacity, $10^{3} \mathrm{~kW} \quad 900 \cdots 270 \quad 630$

2. Capacity factor.

$0.70-0.60$

3. Electricity, $10^{9} \mathrm{kWhr}$

$5.52 \quad 1.42$

$4: 10$

4. Initial investment, $10^{6} \$$

$790 / 963$

55

788

5. Specific initial investment for incremental

capacity, $\$ / \mathrm{kW}$

$1250 / 1530$

$---$

1250

6. Operational \& maintenance cost (as equivalent initial investment), $10^{6} \$$

$1126 / 1203 \quad 433$

1189

7. Specific operation of maintenance cost, $\$ / k W h r$

$0.204 / 0.218$

0.305

0.290

8. Subtotal equivalent capital inyes tment $(4+6)$, $10^{6} \$$

$1916 / 2166$

488

1977

9. Total equivalept capital investment, $10^{6} \$$

$1916 / 2166$

2465

10. Gain in total equivalent capital investment if MHD retrofit alternative is used, $10^{6} \$$

$549 / 299$

11. Relative gain in total equivalent capital investment if MHD retrofit is used $(10 \div 9) \times 100, \%$

$22.3 / 12.1$ 
TABLE 24: Cost Comparison 330/1100 MW(electrical) Power System Description of al ternative

Evaluated MHD retrofit power plant alternative of $1000 \mathrm{MW}($ electrical)

MHD retrofit New power plant alternative

Allternative Existing Power from Power Plant. System Grid
1. Capacity, $10^{3} \mathrm{~kW}$
1100
330
770

2. Capacity factor

0.70

0.65

$---$

3. Electricity, $10^{9} \mathrm{kWhr}$

6.75

1.88

4.87

4. Initial investment, $10^{6} \$$

$951 / 1171$

60

963

5. Specific initial investment for incremental

capacity, $\$ / \mathrm{kW}$

$1235 / 1520$

1250

6. Operational \& maintenance cost (as equivalent initial investment), $10^{6} \$$

$1360 / 1452$

567

1412

7. Specific operation of llidintenance cost, $\$ / \mathrm{kWhr}$

$0.201 / 0.215 \quad 0.302$

0.290

8. Subtotal equivalent capital inves timent $(4+6)$, $10^{6} \$$

$2311 / 2623$

627

2375

9. Total equivalept capital investment, $10^{6} \$$

$2311 / 2623 \cdot 3002$

10. Gain in total equivalent capital investment if MHD retrofit alternative is usen, $1.06 \$$

$691 / 379$

11. Relative gain in total equivalent capital investment if MHD retrofit is used $(10 \div 9) \times 100, \%$

$23.0 / 12.6$ 
Figure 11 is based on a compilation of the results presented in Tables 20-24. The gain in ECI if the required power capacity is filled by retrofitting current coal-fired power plants with MHD, as opposed to retrofitting them with FGD scrubbers and building new coal-fired plants to fill that required capacity. (As in the previous figures, data are plotted to illustrate the range of cost estimates for MHD retrofitting.) As shown by the summary results presented in Figure 12 , it appears that the financial performance of the MHD retrofit alternative is clearly superior to the scrubber retrofit plus incremental coal-fired power plant option at plants of larger capacity. However, these comparisons are based on continued operation of the existing coalfired facility over the lifetime of the power station, and that substantial costs may be associated with maintaining the existing plant in operation. Further, an optimized MHD retrofit design would undoubtedly increase plant performance significantly. Either of these factors could affect the relative benefit of the two alternatives enough to make MHD retrofit of even the Vermilion Boiler \#1 cost effective. However, the final decision on the acceptability of any alternative is a function of the availability of capital, alternate investment possibilities, tax advantages, effluent control, power requirements, and network strategy. Without knowing these factors, no definitive recommendation can be made. Nevertheless, it appears that serious consideration should be given to the MHD concept as a reasonably-priced way of retrofitting an existing coal-fired plant to provide more power while maintaining environmental quality.

\section{Potential Impact of MHD Retrofit on Coal Utilization}

As shown in this report, MHD retrofitting appears to be an economically attractive approach towards meeting the future capacity needs of a utility. If MHD retrofitting were widely applied, it would have significant impact on the national utilization of coal, that is the energy efficiency for the use of this natural resource and the total coal consumption for electric power production. In fact, MHD retrofitting has a greater potential for improving national coal utilization than building new, base-load MHD plants to supply future energy demands. 


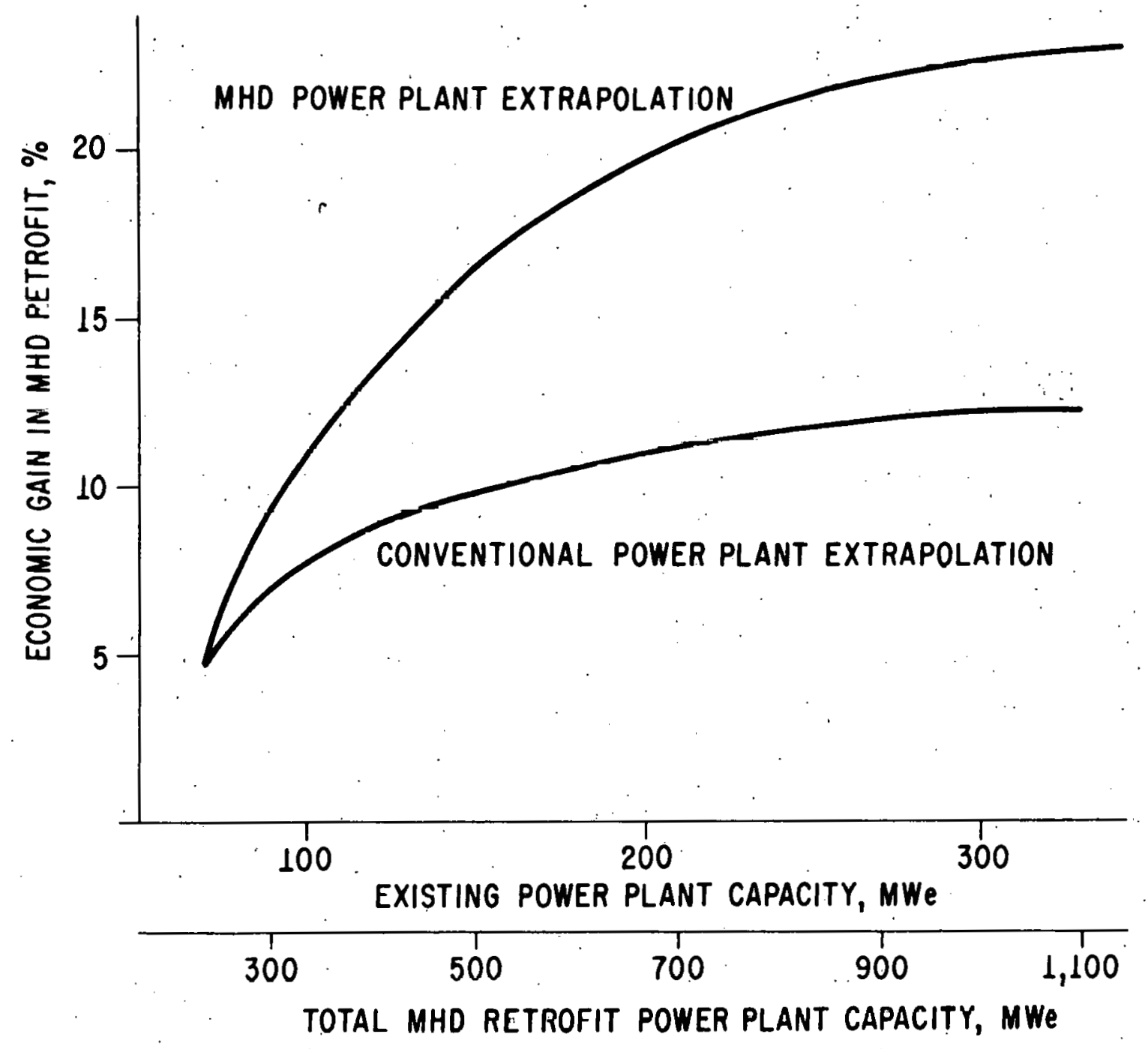

Figure 11: Relative Gain in Total Equivalent Capital Investment for MHD Retrofits of Increasing Capacity 
An estimate of the maximum potential improvement in the energy efficiency can be obtained from current utility forecasts of power production as complied by EPRI [44]. In Table 25; the projected electrical power supplied in 1990 and 2000 are 1 isted by fuel type. The shortfall represents estimated future demand for which utilities currentily have not planned for or have not decided on the fuel type. This uncertainty is a result of many factors, which make forecasting extremely difficult, such as abnormal electrical energy growth and demand patterns, an uncertain national economic condition, new environmental regulations, licensing difficulties, effect of a national energy policy, technical risks associated with emerging technologies, financial risks associated with nuclear energy, the influence of the oil cartell, decilining financial positions of utilities, inability of the U.S. to export significant amounts of coal, state resource removal taxes; tax incentives and many other factors.

The relative overall improvement in energy conversion efficiency possible by introducing a more efficient, technology to supply new demand can be measured by

$$
S=\left(\frac{\Delta \eta}{\eta}\right) \cup \times 100
$$

where $\Delta n$ is the absolute efficiency gain, $n$ the electrical conversion of the base technology, and $U$ is the fraction of the total demand supplied by the more efficient technology.

If it is assumed that new MHD plants will be built to provide the generation increase between 1990 and 2000 . that is to be supplied by coal., $1.1 \times 10^{12} \mathrm{kWhr} / \mathrm{yr}$, and that these MHD plants will have an efficiency of $43-48 \%$ compared to a $38 \%$ efficiency of all other generation technologies. The maximum potential efficiency gain is,

$$
S=\left(\frac{5 \text { to } 10}{38}\right)\left(\frac{1.1}{5.8}\right) \times 100 \approx 2.5 \text { to } 5.0 \% \text {. }
$$

For a second scenario, assume that the MHD retrofit is employed to supply the increased demand and the projected shortfall in the year 2000, because of its lower capital requirements compared to a new plant and its capability of 
TABLE 25: Electricity Generation By-Fuel Type

(Source: Reference 44)

Energy Generation Energy Generation Growth in Energy Generation

Year 1990

( $k$ Wh $\times 10^{-12}$ )

Year 2000

(kWhN $10^{-12}$ )

for Period 1990 to 2000

$k$ Wh $\times 10^{-12}$

\begin{tabular}{llll}
\hline Nuclear & 1.0 & 1.0 & 0 \\
$\begin{array}{l}\text { Hydro, } \\
\text { Geothermal, }\end{array}$ & & & \\
Solar and & & & \\
Biomass & 0.5 & 0.6 & 0.1 \\
Fossil & & & \\
C.nal & 1.5 & 0.1 & 1.1 \\
Coal liquids & 0 & 0.3 & 0.1 \\
0il \& Gas & 0.5 & 3.0 & 1.0 \\
Subtotal & 2.0 & 1.2 & 0.9 \\
Shortfall & 0.3 & 5.8 & 2.0 \\
Total & 3.8 & & \\
\hline
\end{tabular}


overcoming the factors that contributed to this shortfall. The MHD retrofit would be applied to the coal fired plants in existence in 1990, which have an average base efficiency of $36 \%$, and it would increase their efficiency by $5-$ $10 \%$. This scenario would result in an overall efficiency improvement of

$$
S=\left(\frac{5 \text { to } 10}{36}\right)\left(\frac{3.0+1.2}{5.8}\right) \times 100 \approx 10 \text { to } 20 \%
$$

For a final scenario, assume that besides the new generation being planned, all existing coal plant are retrofitted with FGD equipment. In this case, assume a loss of $2 \%$ in efficiency. Hence, the various potential loss is

$$
S=\left[\left(\frac{-2}{38}\right)\left(\frac{1.1}{5.8}\right)+\left(\frac{-2}{36}\right)\left(\frac{1.5}{5.8}\right)\right] \times 100 \approx-2.5 \%
$$

Thus, the capability of the MHD retrofit concept to upgrade the effi- i ciency of existing fossil-fired plants coupled with its larger potential market than new base-load MHD plants, results in a significantly better utilization of our coal resources. Also, to meet new environmental requirements an MHD retrofit is much more attractive then a FGD retrofit. A direct result would be an increase in total consumption of domestic coal resources and a lessened dependence on foreign energy sources. 
THIS PAGE

\section{WAS INTENTIONALLY \\ LEFT BLANK}




\section{SUMMARY}

1. As a result of the escalation of fuel prices, the necessity of changing from oil to coal because of availability, new environmental regulations, and the increasing costs of cooling water and construction sites, the retrofit of existing power plants has become cost effective, in general.

2. The MHD concept has no strong competitors as a method of retrofitting existing coal-fired power plants which also decrease the plant heat rate.

3. To prove the effectiveness of the MHD concept for retrofit, the following investigations were performed: (a) Retrofit requirements and constraints were determined; (b) Previous MHD power plant configurations developed for retrofit applications were evaluated and determined to be impractical; (c) New configurations were developed and analyzed to determine the best configurations and major operating parameters; (d) Thermodynamic and life cost calculations were prepared for Vermilion power plant \#1, to determine feasibility and profitability of the retrofit; (e).A scale-up was prepared, in order to show possible economic efficiency as a function of design capacity for the MHD retrofit concept developed by ANL.

4. Major economic results of the investigation are: (a) An application of the MHD concept to the retrofit becomes effective for power plants of approximately 100-MW (electrical) capacity and larger; (b) Design capacity of the existing power plant can be increased by 100 to $200 \%$; (c) Heat rate can be decreased by 15 to $20 \%$; (d) Compared with other methods of expanding existing power systems, the MHD concept provides a 10 to $20 \%$ reduction in equivalent capital investment; (e) There is a large possible retrofit market; hence, the MHD retrofit could be very profitable business.

5. Major engineering results of the investigation are: (a) It is possible to choose optimum configuration and operating parameters for each power plant retrofit, taking into account specific features of each power system and the plant itself, such as, changing demand for power and electricity, cost of cooling water, environmental regulations, wearing of existing 
equipment, steam conditions, kind of coal, etc: (b) With the MHD concept, it is possible to provide the means for burning different coals (with higher sulfur content), in order to increase reliability of the coal supply, and to change coal supplier, if necessary, to reduce the cost of delivered fuel. 


\section{REFERENCES}

1. Koester, J., "Advances in Coal Fired MHD Generator Research," Proceedings of 16th IECEC, 3, 2210, August 1981.

2. Bityurin, V. et al., "Investigation of the "RM" Diagonal Channel on the U25 Facility, Proceedings of 7 th International Conference on MHD Electrical Power Generation, June 1980.

3. Buznikov, A. E., et al, "Studies of Diagonal MHD Channels at the U-25 Facility during Duration Operation," Fourth U.S.-U.S.S.R. Colloquium on Magnetohydrodynamic Electric Power Generation, October, 1978, Washington, D.C., p. 347 .

4. Kirillin, V. and Sheindlin, A., "Development of the MHD Energy Conversion Methods in the USSR," Proceedings of 7 th International Conference on MHD Electrical Power Generation, 613, June 1980.

5. Demirjian, A., and Hruby, V. J., et al., "Long Duration Channel Development and Testing," Proceedings of 18th Symposium on Engineering Aspects of MHD, June 1979.

6. Staats, G., DeJong, V., Karvinen, R., Carrington, R., and Bauman, L., "CDIF-Activation Completion and Initial MHD Test Results," Proceedings of 16 th IECEC, Vol. 2, 1483, August 1981.

7. Kulesza, P., Owens, S., and Kolbe, R., "Development of a Steam Plant for a Coal-Fired MHD Power Plant," Proceedings of 7 th International Conference on MHD Electrical Power Generation, (1) 322, June 1980.

8. "Feasibiity Study: MHD Retrofit of Steam Power Plants, Summary and Conclusions. (Part 1)," prepared for DOE/MHD Division by Gilbert Commonwealth Engineers, ER-79-12, July 1979.

9. Singh, R. N., and Natesan, K., "Corrosion Behavior of Metallic Materials in the Reducing Environments Characteristic of a Coal-fired MHD Generator," Corrosion 36 (5), 230-241, Mày 1980.

10. Natesan, K. - to be published Argonne National Laboratory 1982.

11. Chow, L.S.H., Schlenger, B. J., and Reed, C. B., "Seed Deposit Tests for an MHD Steam Bottoming Plant," Proceedings of the 19th Symposium on Engineering Aspects of Magnetohydrodynamics,, June 1981 .

12. Bergman, P. D. and Mostinsky, I.L. Ionizing Seed. Open-cycle Magnetohydrodynamic Electrical Power Generation. Chapter 12, M. Petrick and B. Ya. Shumyatsky, editors, Argonne National Laboratory 1978.

13. Styrikovich, M. A. and Mostinsky, I. L. (1976). A Study of the Processes Resulting from the Use of Alkaline Seed in Natural Gas-fired MHD Facilities. Academy of Sciences, Moscow 1976. 


\section{REFERENCES (continued)}

14. Petrick, M., Johnson, T., and Natesan, K., "Development of the Steam Plant for Open Cycle MHD," 1981 Specialists Meeting on Coal-Fired MHD Power Generation, November 1981.

15. Im, Kwan H., Ahluwalia, R. K., and Berry, G. F., "Analysis of Flow, GasParticle Radiation, and Particulate Deposition in Radiant Boilers," ANL/MHD-81-5, Argonne National Laboratory, Argonne, IL., April 1981.

16. Berry, G., "Aspects of Open-Cycle MHD. Affecting Heat and Seed Recovery," Proceedings of 16th IECEC, 2, 1531, August 1981.

17. Im, K., and Chung, P., "Particle Deposition from Turbulent Parallel Streams," ANL/MHU-81-2, 1981.

18. Dennis, C. B. and Berry, G. F., "User's Guide for the GSMP/OCMHD System Code," ANL/MHDm80-7, Argonne National Laboratory, Argonne, IL:, December 1980 .

19. Geyer, H. K., "GPSAP/V2 with Applications to Open-Cycle MHD Systems," ANL/MHD-80-15, Argonne National Laboratory, Argonne, IL., January 1981.

20. Berry, G. F. and Dennis, C. B., "Performance Analysis of the MHD-Steam Combined Cycle, Including the Influence of Cost," ANL/MHD-80-3, Argonne National Laboratory, Argonne, Il.., August 1980.

21. Gilbert/Commonwealth, "Magnetohydrodynamic (MHD) Engineering Test Facility (ETF) 200 MWe Power Plant," Conceptual Design Engineering Report, September 1981 .

22. Bercaw, K., Kigo, H., Warinner, U., and liza, U., "Conceptual. Uesign of the MHD Engineering Test Facility," Proceedings of 16th IECEC, 2, 1512, August 1981

23. Im, K., and Chung, P., "Nucleation and Evolution of Slag Droplets in Coal Combustion," AIChE Journal, 26,. (4), 665, July 1980.

24. Im, K., Patten, J., Johnson, T., and Templemeyer, K., "Condensation and Deposition of Seed in the MHD Bottoming Plant," Proceedings at 18th Symposium on Engineering Aspects of MHD, June 1979.

25. Fialia, S. N., and Elston, C. W., "Five MW Coal-Fired Gas Turbine to be Linked with Steam Unit," Electrical World, 153, No. 8, 1960.

26. White, A. 0., "The Combined Gas-Turbine-Steam-Turbine Cycle with Supercharge Boiler and Its Fuels," Journal of American Society of Mechanical Engineers, No. 264, 1957.

27. Lozhkin, A. N. and Geltman, A. E., "Power Plants with Combined Steam-Gas Cycle of Constant Pressure Combustion;" Combined Power Plants and Cycles (in Russian), TSKTI, 1952. 
28. Im, K. H., "Estimates of Slag and Seed Deposition on the Heat Exchanger Surfaces of the MHD Bottoming Plant," memorandum to G. Berry, Argonne National Laboratory, ENG/AP/8058, March 9, 1981.

29. Hardgrove, J., "MHD Coal Combustor Development Status," Proceedings of 16 th IECEC, 2, 1471, August 1981.

30. Springman, H., Greenberg, R., and Juhasa, A. J., "The Optimization of Air Separation Plants for Combined Cycle MHD Power Plant Applications," Proceedings of $7 \mathrm{th}$ International Conference on MHD Electrical Power Generation, 403, June 1980.

31. Mazza, R. J.,. "Life-Cycle Cost Comparison Report prepared for Argonne National Laboratory," Sargent and Lundy Engineers, Chicago, May 1981.

32. Eisenberg, S. L., "Power Plant Retrofit Life-Cycle Cost Financial Analysis," Lester B. Knight and Associates, Inc., April 1981.

33. Technical As sessment Guide, EPRI-PS-1201; SR, July 1979

34. F. A. Hals, "Parametric Study of Potential Early Commercial MHD Power Plants," NASA CR-159633, December 1979.

35. "Study of Seed Reprocessing. Systems for Coal-Fired, Open-Cycle MHD Power Plants," PMD-80-1471, Babcock and Wilcox Co., and J. E. Sirrine Co., June 1980 .

36. "Mill Applications of the Tampella Recovery Process," 1972 International Sulfite Pulping and Recovery Conference, October 1972.

37. Personal Communication, D. J. Chidley, Commonwealth Edison, to S. L. Eisenberg, Lester B. Knight and Associates, October 17, 1980.

38. Minkov, V., and Leonkov, A., "Comparative Economic Effectiveness of Power Plant Moderization," Izvestiia. Vysshikh Vchebnykh Zavedenii, Energetika, September 1976 (in Russtan)

39. Minkov, V., Stepanchuk, V., "Development of Optimal Process Heat and Power Plant Systems Being Designed for Nuclear Fuels," Izvestiia Akademi-i Nauk BSSR, Ser-yia Fiziko-Energeticheskikh Nauk, January 1978 (in Russian).

40. Budwahi, R. N., "Power Plant Capital Cost Analysis,". Power Engineering, May 1980.

41. Nuclear Power Engineering: Analysis of Trends in Policy and Technology. Power Engineering, October 1980.

42. Lincoln, R. A., "How to Avoid Common Errors in Life-cycle cost Comparisons," Power, May 1981, 


\section{REFERENCES (continued)}

43. Musick, C. R., and Knapp, R. W., "C-E Meets Utility Load Change Capability. Needs with 80th NSSS," Combustion, September 1979.

44. Starr, C., "Choosing Air Energy Future," EPRI Journal, Sept. 1980.

45. Berry, G., and Dennis, C., "Performance Analysis of the MHD Steam Combined Cycle Including the Influence of Cost," Symposium on Instrumentation and Control for Fossil Energy Process, June 1981.

46. Geyer, H., and Berry, G., "Off-Design Analysis of an MHD Power Plant with Oxygen Enrichment," AIAA Aerospace Science Conf., 81-0319, January 1981.

47. Geyer, H. K., and Berry, G. F., "A Proprocessor for Performing Lumped Component Systemins Analysis," International Energy Symposium, SFE-81-75, May 1981. 


\section{APPENDIX: COMPUTER ANALYSIS}

In recent years ANL/ENG Systems Analysis: Group has developed a generalized system analysis code, particularly suitable for simulation of power plants $[18,19,20,45,46,47]$. Throughout the period of its development, the goal has been a generalized concept, structured to allow simulation of many types of systems, as well" as provide a way to simulate a particular system with a range of complexity: The basis philosophy of ANL/ENG Systems Code development has been interchangeability, based on code structure and level: The executive codes make no reference to any physical system. As a driver; it is used only to control the solution of the problem - input, output, parameter sweeps, optimization, graphics -- and so can used to model many different kinds of systems. To connect the executive level with the models of the particular system (e.g., fuel cells, gasification combined cycle, community energy systems) an interface procedure is used. All property data are stored at the lowest Systems Code level. Because of this structuredlevel format, it is less difficult to modify or replace the procedures and in particular, the models of the components under investigation. Assuming all models are written in the same. structured-level format, it would be a straightforward process to switch from a simplified model of a specific component to a more sophisticated one or to replace it entirely with a model of some different component. In this way the ANL/ENG Systems Code can provide simulation of many types of systems or simulate a particular system with a range of complexity, depending on the groups of models selected.

Calculation of the heat balance for MHD retrofit design of a power plant is not a quickly accomplished task. Even if the retrofit design is fixed, a permutation to a steam pressure or gas mass fiow rate; for example, requires a new heat balance calculation. Compound this with the need to vary the design itself while maintaining constraints, such as, different environmental conditions and regulations, different fuel properties and costs, instability in coal properties, different cooling water costs, or the instability in the electrical load demand, and the number of calculations becomes formidable. The need for a computerized systems code is obvious and, further, one with both design and off-design capabilities. ANL's General Purpose System Analysis Program (GPSAP) was developed with these capabilities in mind. 
GPSAP treats both the individual power plant component. models (compressors, turbines, heat exchangers, etc.) as well as the streams flowing through them (gas, steam, air, coal, etc.) independently. The order of the components, i.e., the path of the fluids, and also the parameters associated with them can be altered quite easily so that a complete heat balance calculation can be performed for the modified design very quickly. Theoretically, this means that the effect of merely changing the pressure of a pump or reordering the entire steam-water flow, for example, can be known in a matter of minutes. Realistically, problems can arise in achieving a successfully converged run at the first attempt due to poor judgement in choosing the input initial values, ranges of the fluid flow parameters to be varied, and in determination of the constraints defining the design itself.. The ease involved in running the code, however, makes this a benefit to the system designer as opposed to a hindrance because error in judgement in choosing a design is quickly noted and corrected. 
Internal:
E. S. Beckjord
C. B. Dennis (5)
R. B. Poeppe 1
C. E. Till
E. D. Doss
W. C. Redman
E. G. Pewitt
P. F. Dunn
C. B. Reed
L. Burris
H. K. Geyer
B. J. Sch lenger
B. R. T. Frost
K. H. Im
R. A. Lewis
C. E. Johnson
M. H. Shackelford
R. S. Zeno
I. Johnson
M. Petrick (12)
T. R. Johnson (5)
R. K. Ahluwalia
A. A. Jonke
A. J. Sistino
R.. S. Smith
D. Baurac
T. F. Kassner
B. K. Snyder
G. F. Berry (5)
C. R. Kennedy
S. Vanka
P. E. Blackburn
K. D. Kuczen
D. K. Warinner
D. S. Webster
D. H. Bomk amp
V. Minkov (5)
R. W: Weeks
L. T. Bryant
K. Natesan
F. A. Cafasso
Y. Pan
L. W. Carlson
J.' Y. Park
M. G. Chasanov
C. V. Pearson
L. S. Chow
B. Picologlou
E. S. Pierson
G. A. Whittington
A. B. Krisciunas
ANL Patent Dept.
ANL Contract File
ANL Libraries
TIS Files (6)

\section{External:}

DOE-TIC for distribution per. UC-90g and UC-93 (282)

Manager, Chicago Operations Office, DOE

$F$. Herbaty, DOE-CH

J. Horowitz, DOE-CH

J. 0. Hunze, DOE-CH

President, Argonne Universities Association

AUA Review Committee for MHD:

C. B. Alcock, U. Toronto

D. Berg, Carnegie-Mellon U:

C. H. Kruger, Jr., Stanford U.

S. J: Townsend, S.J.T. Consultants, Ltd.

T. D. Wheelock, Iowa State U.

Y. C. L. S. Wu, U. Tennessee Space Inst.

P. Zygielbaum, Electric Püwer Résedrch Irisl.

DOE/Office of MHD, Washington:

V. Der

J. Epstein

J. Hopenfeld

J. Klepe is

R. Lightner

M. Mintz

G. Rudins

S. Sacks

D. Shelor

M. Sluyter (2)

L. Sullivan

K. Woodcock

R. Wright 
C. Kolb, Aerodyne Research, Inc., Bedford, Mass.

R. Cooper, Air Force Aero Propulsion Lab., Wright-Patterson AFB

M. K. Guha, American Electric Power Service Corp., New York City

Mr. Roepke, Arnold Engineering Development Center, Arnold A. F. Station, Tenn.

$L$. Whitehead, Arnold Engineering Development Center--CALSPAN, Tullahoma

F. Hals, Avco Everett Research Lab., Everett, Mass.

R. Kessler, Avco Everett Research Lab., Everett, Mass.

P. R. Probert, Babcock and Wilcox, Barberton

J. L. Bates, Battelle Pac if ic Northwest Lab.

B. Wasserman, Dynatrend, Inc., Woburn, Mass.

A. C. Dolbec, Electric Power Research Inst.

R. J. Ferraro, Electric Power. Research Inst:

D. DeCoursin, Fluidyne Engineer ing Corp., Minneapol is

M. Freeman, Fusion Magazine, New York City

General Electric Research Labs., Chief Librarian, Schenectady

L. Terrey, General Electric Co., Philadelphia

B. Zauderer, General Electric Co., Philadelphia

J. Cutting, Gilbert Associates, Inc., Reading, Pa.

P. M. Chung, U. Illino is, Chicago

A. Dawson, Massachusetts Inst. Technology (2)

D. B. Montgomery, Massachusetts Inst. Technology

J. F. Louis, Massachusetts Inst. Technology

D. Murphree, Mississippi State U.

F. Diebold, Montana College of Mineral Science and Technology, Butte

A. Greenberg, Mont ana Energy and MHD R\&D Inst.; Butte

J. D. Meglen, Mont ana Energy and MHD R\&D Inst., Butte

G. E. Youngblood, Montana Energy and MHD R\&D Inst., Butte

R. Rosa, Montana State U., Bozeman

F. Fogarty, Mountain States Energy, Inc., Butte

G. R. Seikel, NASA Lewis Research Center

R. J. Sovie, NASA Lewis Research Center

S. Schneider, National Bureau of Standards, Washington (2)

R. A. Carabetta, Pittsburgh Energy Technology Center (2)

M. Bloom, Polytechnic Inst. of New York, Farmingdale

R. Viskanta, Purdue U.

R. Y. Pei, Rand Corp., Washington

F. G. Blottner, Sandia National Labs., Albuquerque

K. E. Tempelmeyer, Southern Illino is U., Carbondale

S. Demetriades, STD Corp., Arcadia, Calif.

C. Maxwe 11, STD Corp., Arcadia, Calif.

A. Manaker, Tennessee Valley Authority, Chattanooga

H. Graham, TRW, Redondo Beach

J. Hardgrove, TRW, Redondo Beach

R. Schirk, Butte Project office, USDOE

W. Buss, U. Tenriessee Space Inst.

J. N. Chapman, U. Tennessee Space Inst.

J. B. Dicks; U. Tennessee Space Inst.

E. Lahoda, Westinghouse Research and Development Lab., Pittsburgh

F. D. Retallick, Westinghouse Advanced Energy Systems Div.. Pittsburgh

J. Sadler, Westinghouse Advanced Energy Systems Div., Pittsburgh

B. Rossing, Westinghouse Electric Corp., Pittsburgh 